Energy

Elsevier Editorial System(tm) for Renewable

Manuscript Draft

Manuscript Number: RENE-D-18-00896R1

Title: Research on a Cost-effective Measure Dedicated to Stabilizing

offshore Wind Farm Crew Transfer Vessels

Article Type: Research Paper

Keywords: Offshore wind farm; crew transfer vessel; motion stability;

Response amplitude operator

Corresponding Author: Dr. Wenxian Yang, PhD

Corresponding Author's Institution: Newcastle University

First Author: Wenxian Yang, PhD

Order of Authors: Wenxian Yang, PhD; Wenye Tian; Kexiang Wei; Zhike Peng; Zhonghua Huang

Abstract: The rapidly growing offshore wind industry is calling for more crew transfer vessels to deliver the increasing number of minor maintenance tasks. This is because $75 \%$ of onshore turbine failures are related to the minor errors occurring in the electrical and power electronic systems of the turbines. The figure in offshore scenario may be worse due to the wet, salty and corrosive sea air. Limited by the small hull and deck spaces, the proven motion stabilization techniques can hardly be applied to crew transfer vessels. Therefore, the present crew transfer vessels have very limited capability to provide safe transfer between the vessel and the turbines particularly in rough sea waves. To tackle this issue, a new motion stabilization measure is researched in this paper. Through conducting both numerical and experimental researches to investigate the motions of the vessel under different wave conditions before and after applying the proposed measure, it is found that heave-plate based measure does work effectively in stabilizing the motion of the vessel especially in resonant frequency regions. Moreover, the effect of the heave plates on motion reduction can be further enhanced through optimizing their size and the underwater depth at which the plates are placed. 


\title{
Research on a Cost-effective Measure Dedicated to Stabilizing Offshore Wind Farm Crew Transfer Vessels
}

\author{
Wenxian Yang ${ }^{1}$, Wenye Tian ${ }^{1}$, Kexiang Wei ${ }^{2}$, Zhike Peng ${ }^{3}$, Zhonghua Huang ${ }^{2}$ \\ ${ }^{1}$ School of Engineering, Newcastle University, Newcastle upon Tyne NE1 7RU, UK \\ ${ }^{2}$ Hunan Province Cooperative Innovation Centre for Wind Power Equipment and Energy Conversion, \\ Hunan Institute of Engineering, Xiangtan 411104, China \\ ${ }^{3}$ State Key Laboratory of Mechanical System and Vibration, Shanghai Jiaotong University, Shanghai \\ 200240, China
}

\begin{abstract}
The rapidly growing offshore wind industry is calling for more crew transfer vessels to deliver increasing number of minor maintenance tasks as about $75 \%$ of onshore wind turbine failures are related to the minor errors occurring in the electrical and power electronic systems of the turbines. The situation in offshore wind farms may be worse due to the wet, salty and corrosive air in offshore environments. Due to the limitations of small hull and deck spaces, there is difficulty to apply the proven motion stabilization techniques to wind farm crew transfer vessels. Consequently, the present crew transfer vessels have limited capability in providing safe transfer between the vessel and wind turbines, particularly in rough sea waves. To tackle this issue, a new motion stabilization technique is studied in this paper by using both numerical analysis and experimental testing approaches. Through investigating the vessel's motions under different wave conditions before and after applying the proposed technique, it is found that the heave, roll and pitch motions of the vessel, especially in its resonant frequency regions, have been successfully constrained after applying the proposed stabilizing technique. Moreover, the amount of motion reduction can be further improved through optimizing the size of stabilizers and their underwater distance.
\end{abstract}

\section{Keywords}

Offshore wind farm; crew transfer vessel; motion stability; response amplitude operator 
Dear professors,

We have completed the revision of our paper based on the reviewers' advices and comments point by point. Now, we are submitting the revised version of the paper to you for further review. All major revisions have been highlighted in the revised paper.

Look forward to your early reply.

Best wishes and regards

Wenxian Yang (on behalf of other co-authors) 


\title{
Responses to the Reviewers' Questions and Comments
}

\author{
Paper No.: RENE-D-18-00896
}

\begin{tabular}{|c|c|c|}
\hline \multicolumn{3}{|c|}{ Reviewer \#1 } \\
\hline No. & Comments & Responses \\
\hline 1 & $\begin{array}{l}\text { I think it is relevant and interesting. } \\
\text { The only thing I suggest to improve is } \\
\text { to add a literature review presenting } \\
\text { other concepts and respective research. }\end{array}$ & $\begin{array}{l}\text { Thank you very much for this positive comment. } \\
\text { Three literature review papers on ship motion stabilizing } \\
\text { techniques and two journal papers that discuss the } \\
\text { contribution of heave plate to suppressing the motion of } \\
\text { floating structures have been supplemented in revision. } \\
\text { They are References [10-12] on Page } 3 \text { and References } \\
{[13,14] \text { on Page } 4 \text {. Both of them have been highlighted in }} \\
\text { the revised paper. }\end{array}$ \\
\hline \multicolumn{3}{|c|}{ Reviewer \#2 } \\
\hline 1 & $\begin{array}{l}\text { Convergence test of the numerical } \\
\text { model: The authors need to conduct } \\
\text { convergence test regarding the mesh } \\
\text { they used in the numerical model. }\end{array}$ & $\begin{array}{l}\text { Thank you very much for reminder. } \\
\text { Convergence testing results and the relevant descriptions } \\
\text { and discussions have been supplemented in revision and } \\
\text { highlighted on Page } 5 \text { and Page } 6 \text {. }\end{array}$ \\
\hline 2 & $\begin{array}{l}\text { It is better to provide a reference of } \\
\mathrm{EQ}(4) \text {. }\end{array}$ & $\begin{array}{l}\text { Reference of Eq.(4) has been added. It is Reference [15] in } \\
\text { the revised paper. }\end{array}$ \\
\hline 3 & $\begin{array}{l}\text { Figure 4: Is the line come from curve } \\
\text { fitting with limited data points. Since } \\
\text { this data obtained from numerical } \\
\text { simulation. I would expect more data } \\
\text { points can be obtained from numerical } \\
\text { simulation. }\end{array}$ & $\begin{array}{l}\text { Yes, the curves are data fitting results from the limited data } \\
\text { points obtained from CFD calculations. } \\
\text { More data points have been added on the curves to indicate } \\
\text { the variation tendencies of the RAOs. }\end{array}$ \\
\hline 4 & $\begin{array}{l}\text { Compare Figures } 4 \& 8 \text {, the results } \\
\text { form numerical simulation and } \\
\text { experimental data are quire difference. } \\
\text { This requires some discussion and } \\
\text { explanation. }\end{array}$ & $\begin{array}{l}\text { The relevant discussions and explanations have been added } \\
\text { and highlighted in the section following Fig. } 9 \text { in the revised } \\
\text { paper. } \\
\text { The comparison of Fig. } 5 \text { and Fig. } 9 \text { interestingly indicates } \\
\text { that the effect of heave plate on the vessel's motion stability } \\
\text { can be more clearly observed from the experimental results } \\
\text { in Fig. } 9 \text { rather than from the numerical simulation results in } \\
\text { Fig. } 5 \text {. This is because water is a viscous fluid. The viscosity } \\
\text { of water will amplify the motion reduction effect of the } \\
\text { heave plates. However, the viscosity of water is neglected } \\
\text { in the CFD calculations to ensure the differential } \\
\text { hydrodynamics equations to be tractable. }\end{array}$ \\
\hline
\end{tabular}




\section{Highlights}

1. A new cost-effective technique is studied dedicated to stabilizing the motion of offshore wind farm crew transfer vessels;

2. Heave plate does work effectively in reducing the motions of the crew transfer vessel particularly in the resonant frequency region of the vessel;

3. The motion reduction capability of the heave plates can be further improved by optimizing their size and underwater distance. 


\title{
Research on a Cost-effective Measure Dedicated to
}

\section{Stabilizing Offshore Wind Farm Crew Transfer Vessels}

\author{
Wenxian Yang ${ }^{1}$, Wenye Tian ${ }^{1}$, Kexiang Wei ${ }^{2}$, Zhike Peng ${ }^{3}$, Zhonghua Huang ${ }^{2}$ \\ ${ }^{1}$ School of Engineering, Newcastle University, Newcastle upon Tyne NE1 7RU, UK \\ ${ }^{2}$ Hunan Province Cooperative Innovation Centre for Wind Power Equipment and Energy Conversion, \\ Hunan Institute of Engineering, Xiangtan 411104, China \\ ${ }^{3}$ State Key Laboratory of Mechanical System and Vibration, Shanghai Jiaotong University, Shanghai \\ 200240, China
}

\begin{abstract}
The rapidly growing offshore wind industry is calling for more crew transfer vessels to deliver increasing number of minor maintenance tasks as about $75 \%$ of onshore wind turbine failures are related to the minor errors occurring in the electrical and power electronic systems of the turbines. The situation in offshore wind farms may be worse due to the wet, salty and corrosive air in offshore environments. Due to the limitations of small hull and deck spaces, there is difficulty to apply the proven motion stabilization techniques to wind farm crew transfer vessels. Consequently, the present crew transfer vessels have limited capability in providing safe transfer between the vessel and wind turbines, particularly in rough sea waves. To tackle this issue, a new motion stabilization technique is studied in this paper by using both numerical analysis and experimental testing approaches. Through investigating the vessel's motions under different wave conditions before and after applying the proposed technique, it is found that the heave, roll and pitch motions of the vessel, especially in its resonant frequency regions, have been successfully constrained after applying the proposed stabilizing technique. Moreover, the amount of motion reduction can be further improved through optimizing the size of stabilizers and their underwater distance.
\end{abstract}

\section{Keywords}

Offshore wind farm; crew transfer vessel; motion stability; response amplitude operator 


\section{Background}

Together with solar, hydro-power, geothermal and other renewable energy forms as well as the emergence of sophisticated grid management and affordable energy storage, wind is playing an increasingly vital role in developing a fossil-free power society. According to the annual market report released by the Global Wind Energy Council (GWEC), the annual installed wind capacity is 52,573 MW in 2017. This brings the global total installed wind capacity to 539,581 MW, of which $3.5 \%$ is from offshore [1]. There is no doubt that the present offshore wind industry is in infancy and its market share is still 'tiny'. However, exploiting offshore wind resources has become an irreversible tendency in the wind industry attributing to the stable and high wind speed offshore and the absence of land use issues in open sea. According to the recent survey by the GWEC, the total installed offshore wind capacity has reached 18,814 MW by the end of 2017, versus 14,483 MW in 2016 and $12,167 \mathrm{MW}$ in 2015 [1]. It is sure that such a growing tendency will continue in the following years. Take the UK offshore wind market as an example, the installed offshore wind capacity is predicted to increase from the present $5.07 \mathrm{GW}$ to $10 \mathrm{GW}$ by 2020 , which will attract $£ 16-21$ bn more investment into the UK market [2]. That means that there will be thousands of wind turbines scattering in a very large sea area. Due to the harsh offshore environment and limited maintenance window of offshore wind farms, how to access so many wind turbines and ensure their safe operation over the whole service life has become a challenging and difficult issue that must be urgently solved today.

At present, helicopter and wind farm service vessel (WFSV) are two major tools used for accessing offshore wind farms and the latter is comparatively cheap in practical application [3]. To date, there have been more than 250 WFSVs are serving in the UK offshore wind market and the fleet is still growing to meet the expanding market of offshore wind [4]. Among these vessels, some are large in size and designed for conducting major maintenance tasks. They are equipped with powerful cranes (for lifting large and heavy wind turbine components to heights) and advanced wave compensation system (for providing safe transfer between the vessel and wind turbines, such as the A400 gangway system developed by Vroon Offshore Services and Ampelmann [5]). But in contrast to these large maintenance vessels, more WFSWs are crew transfer vessels that are small in size and designed for transferring maintenance crews and delivering minor maintenance tasks. Moreover, it is believed that a larger number of vessels of the kind will be demanded by future offshore wind farms. This is because the electrical and power electronic components in wind turbines are more vulnerable to failure than their mechanical counterparts, whilst the failures of these kinds of systems can be fixed via minor maintenance. For example, the survey has shown that about $75 \%$ of onshore wind turbine failures are related to the minor errors occurring in the electrical and power electronic control systems of the turbines [6,7]. There is no doubt that the wet, salty and corrosive air in offshore environments will worsen the situation in offshore wind farms [8,9]. The crew transfer vessels are usually $14-20 \mathrm{~m}$ long and are allowed to operate only when the significant wave height is less than $1.8 \mathrm{~m}$. Due to the 
small hull and limited deck spaces, they are not equipped with proven motion stabilization and wave compensation system. Consequently, their seakeeping performance is relatively poor particularly in rough waves. Therefore, they are unable to provide sufficiently safe transfer between the vessel and wind turbines. However, the safe transfer between the vessel and wind turbines is crucial in the operation and maintenance of offshore wind turbines as unsafe transfer would place the maintenance crew at a high risk of injury. It can also cause serious damage to the wind turbines, as illustrated in Fig.1.

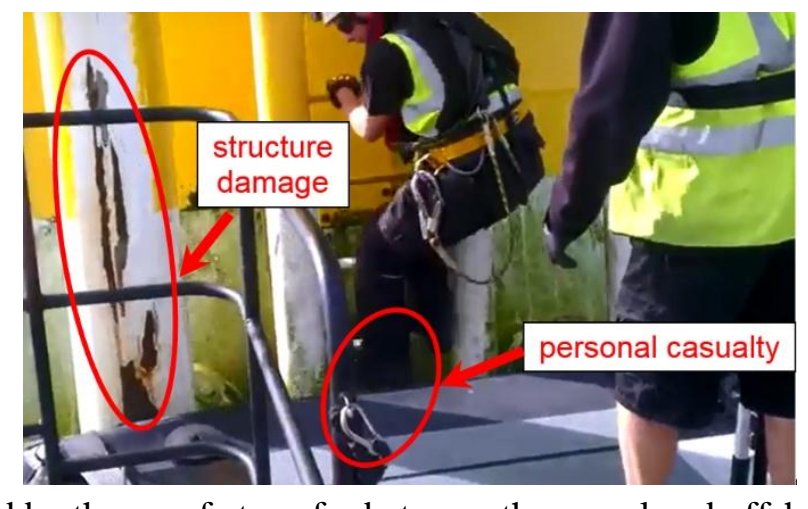

The unsafe transfer between the crew transfer vessel and wind turbines is largely due to the poor seakeeping performance of the vessel (i.e. unstable motion of the vessel in rough waves). However, the proven vessel motion stabilization techniques (e.g. gyro stabilizer, active fin stabilizer, anti-rolling tanks, active ballast system, etc.) that have been reviewed in [10-12] and popularly used in large vessels are not applicable to crew transfer vessels due to the small hull and limited deck spaces of the vessels. In order to address this issue, many techniques and methods, either simple or complex, have been attempted in the past years. Among these techniques, two most popular ones are illustrated in Fig.2.

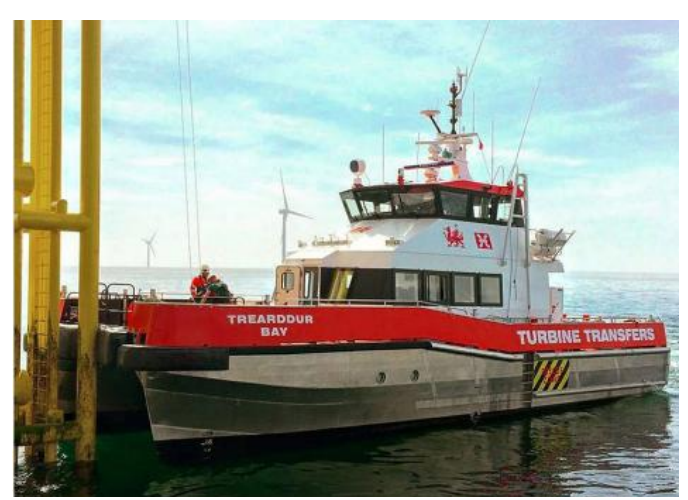

(a) Rubber bumper system

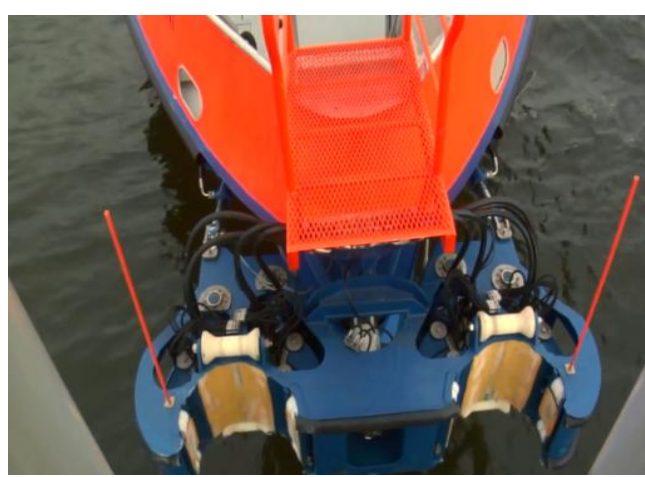

(b) Hydraulic gripper system

Fig.2 Two most popular techniques for achieving safe transfer between crew transfer vessels and offshore wind turbines 
(1) Rubber bumper system - realizes access by creating frictional contact between the vessel and the ladder of offshore wind turbines. The rubber bumper on the vessel bow will form the contact point. To limit the vessel's motions at the point of contact, one has to keep the thrusters running over the whole period to push the boat against the turbine to create sufficient friction. Such a method is limited by wave conditions, e.g. the vessel may lose its contact with the turbine when wave condition is rough. That will make the safe transfer between the vessel and wind turbines no longer possible. Moreover, the thrusters are kept running in the whole period, which makes the transfer uneconomical on fuel. In addition, the huge pushing force by the thrusters may cause potential damage to the structures of wind turbines, see Fig.1. Where, the paint on wind turbine structure was seriously damaged by the vessel. As a consequence of the loss of paints, the turbine structure is exposed in the sea water and/or wet air. That will cause corrosion of the structure if not being repaired in time;

(2) Hydraulic gripper system - enables the vessel to grip turbine ladder using two hydraulic grippers. It reduces the friction-induced damage to turbine structure via rollers. In comparison of the aforementioned rubber bumper system, it does not request the thrusters to keep running after the vessel is locked on turbine ladder by hydraulic grippers. Therefore, it allows fuel saving. However, due to the almost fixed contact point the deck of the vessel may be flooded when experiencing rough waves, making transfer not safe anymore.

In order to improve the safe transfer between the crew transfer vessel and offshore wind turbines, a new motion stabilization technique is numerically and experimentally studied in this paper with the aid of software ANSYS AQWA and the marine testing facilities in the hydro-laboratory of Newcastle University. This new vessel stabilizing technique is proposed with the inspiration of the great contribution of heave plate to suppressing the heave motion of floating structures [13,14]. The major research interest of this paper is to investigate the contributions of heave plates to the motion stability of the vessel, particularly in heave, roll and pitch directions that are critical to the safety of transfer. The influences of the size of heave plates and their underwater distance on the motions of the vessel are investigated under various wave conditions by using both numerical analysis and experimental testing approaches. The investigation results have shown that the proposed motion stabilization technique does effectively constrain the motions of the vessel in all six degree of freedom. Moreover, the proposed technique is cheap and easy to deploy on the crew transfer vessels in contrast to those existing proven motion stabilization measures.

\section{Numerical Research}

\subsection{Numerical model}

127 In order to facilitate the numerical research, firstly a computational fluid dynamics (CFD) model of 128 the offshore wind farm crew transfer vessels was developed in ANSYS AQWA, as shown in Fig.3. It 
is $5.61 \mathrm{~m}$ long, $1.65 \mathrm{~m}$ wide, and $0.7 \mathrm{~m}$ high. Its draft is $0.3 \mathrm{~m}$ and it is assumed to operate in $30 \mathrm{~m}$ depth water. Four extendable 'legs' are designed in the model in order to place the heave plates at different underwater distances. A point mass, $m=2330.90 \mathrm{~kg}$, was defined to indicate the mass and the centre of gravity of the vessel. The moment of inertia of the model is estimated by

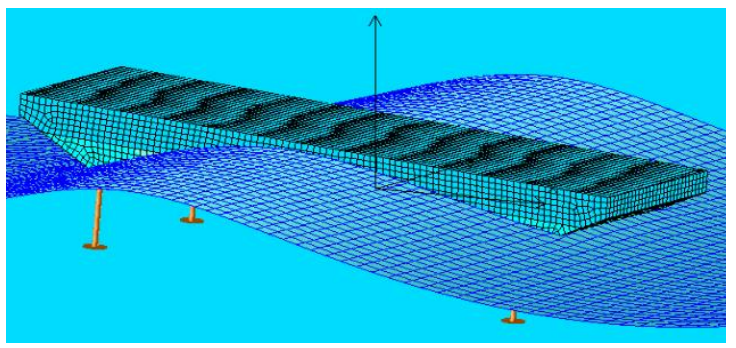

Fig.3 Numerical model of the crew transfer vessel when wave direction angle is 0 degree

$$
I_{i, j}= \begin{cases}m \times r_{i, j}^{2} & \text { when } i=j \\ 0 & \text { when } i \neq j\end{cases}
$$

where $i, j=1,2$ and 3. $r_{i, j}$ refers to the radius of gyration in different directions. Given the length and beam of the vessel are respectively $L$ and $B$, then the value of $r_{i, j}$ can be estimated by

$$
\left\{\begin{array}{l}
r_{1,1}=0.34 \times L \\
r_{2,2}=0.25 \times B \\
r_{3,3}=0.26 \times B
\end{array}\right.
$$

Using (1) and (2), it can be readily obtained that $I_{1,1}=8415 \mathrm{~kg} \cdot \mathrm{m}^{2}, I_{2,2}=392 \mathrm{~kg} \cdot \mathrm{m}^{2}$, and $I_{3,3}=431 \mathrm{~kg} \cdot \mathrm{m}^{2}$, respectively.

In order to obtain a reliable prediction to the motion stabilization effect of the proposed technique, the meshing method of the CFD model is carefully considered before starting the numerical calculations. The CFD model was discretized by using different sizes of elements, and then the ideal meshing method can be readily identified from convergence curves. For example, the convergence curve of the vessel's Response Amplitude Operator (RAO) in pitch direction obtained at wave frequency of $0.5 \mathrm{~Hz}$ is shown in Fig.4. Herein, it is essential to note that the RAO is a transfer function used to reflect the effect of sea waves on the motion of a floating structure.

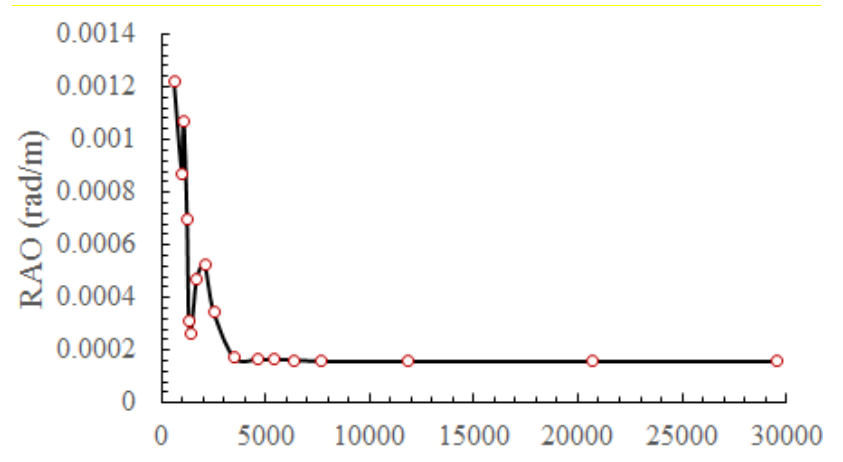

Number of nodes

Fig.4 Convergence of the pitch motion of the vessel against different number of nodes 
From Fig.4, it is seen that with the increase of the number of nodes (i.e. decreasing size of meshing elements), the calculated value of the pitch RAO shows a general decreasing tendency with the increasing number of nodes. The value of the RAO finally reaches a saturated value of 0.000157 $\mathrm{rad} / \mathrm{m}$ when the number of nodes is 20,700 , which corresponds to the maximum element size of 0.06 $\mathrm{m}$. This suggests that a reliable prediction to the vessel's motions can be achieved from the numerical CFD calculations as long as the maximum element size is smaller than $0.06 \mathrm{~m}$. Therefore, the maximum element size is set to be $0.05 \mathrm{~m}$ in the following calculations in order to fully guarantee the reliability of the research conclusions drawn from the following numerical investigations. Accordingly, the corresponding value of defeaturing tolerance was set to be 0.025 in the following numerical calculations as the defeaturing tolerance must be two times smaller than the maximum element size. The meshing details are listed in Table 1. It is worth noting that the model meshing in this research was implemented only on the surface of the model as the 'vessel' is a shell structure. Therefore, only the maximum element size is needed to define in the meshing processing. The actual size and the type of individual meshes will be automatically determined by the software based on the local changes of the model geometries and waves.

Table 1. Meshing details

\begin{tabular}{c|c|c|c|c}
\hline Parameter & No. of nodes & No. of elements & $\begin{array}{c}\text { No. of diffracting } \\
\text { nodes }\end{array}$ & $\begin{array}{c}\text { No. of diffracting } \\
\text { elements }\end{array}$ \\
\hline Value & 29,556 & 29,100 & 13,165 & 12,967 \\
\hline
\end{tabular}

Before proceeding to numerical calculation, some software settings need to be defined as well in advance. The details of these settings are listed in Table 2 to enable the interested readers to repeat the calculations.

Table 2. Software analysis settings

\begin{tabular}{l|c}
\hline Parallel Processing & Program Controlled \\
\hline Generate Wave Grid Pressures & Yes \\
\hline Wave Grid Size Factor & 2 \\
\hline Ignore Modelling Rule Violations & Yes \\
\hline Calculate Extreme Low/High Frequencies & Yes \\
\hline Calculate Drift Coefficients & Yes \\
\hline Include Multi-Directional Wave Interaction & Yes \\
\hline Near Field Solution & Program Controlled \\
\hline Linearized Morison Drag & Yes \\
\hline ASCII Hydrodynamic Database & No \\
\hline Example of Hydrodynamic Database & No \\
\hline
\end{tabular}

In Table 2, the item 'Ignore Modelling Rule Violations' was set to be 'Yes', so that the software is allowed to give alert once an error occurs in the calculation. Otherwise, the software will stop 
calculation without giving any warning when an error occurs. In addition, the item 'Linearized Morison Drag' should be set to be 'Yes' too, allowing the heave plates and the 'vessel' to be simulated as one structure. Otherwise, the heave plates will not be simulated in the calculation if the status of this item was set to be 'No'. Moreover, only after the status of the item 'Linearized Morison Drag' is set to be 'Yes', an irregular wave spectrum (e.g. Pierson-Moskowitz) is allowed to be inserted into the hydrodynamic diffraction to activate the heave plates.

\subsection{CFD calculations}

With the completion of all the aforementioned settings, the motion stability of the vessel equipped with four heave plates are investigated under beam sea conditions (i.e. sea waves approach the vessel from broadside). In order to simplify the calculations, the same significant wave height 10 $\mathrm{m}$ was considered in all of the following calculations, whilst the wave frequency was designed to change gradually from 0 to $1 \mathrm{~Hz}$. As usual, the RAO is employed to assess the stability of the vessel in all six degree of freedom. The software will automatically calculate the vessel's RAOs in all directions upon the completion of CFD calculations. In order to investigate the influences of the size and underwater distance of the heave plates on the motions of the crew transfer vessel, five different underwater distances, i.e. $0.5,0.7,1.0,1.2$ and $1.5 \mathrm{~m}$, and six different diameters of the heave plates, i.e. $0,0.1,0.2,0.3,0.4$ and $0.5 \mathrm{~m}$, are considered in numerical investigations. Therefore, the whole numerical investigation consists of the following two parts:

Part I - is to investigate the influences of the size of heave plates on the motions of the vessel under various wave conditions. In this part, the size of heave plates is variable, while their underwater distance is fixed. To ease understanding, the RAOs of the vessel in all six directions are shown in Fig.5, which are obtained when the underwater distance is $1 \mathrm{~m}$ and the diameter of the heave plates is respectively $0,0.1,0.2,0.3,0.4$, and $0.5 \mathrm{~m}$. Herein, diameter ' $0 \mathrm{~m}$ ' means that there is no heave plate is applied to the vessel. Considering the motion stability of the vessel can be best assessed when resonant vibration happens, only the calculated RAOs in the resonant regions of the vessel are analysed.

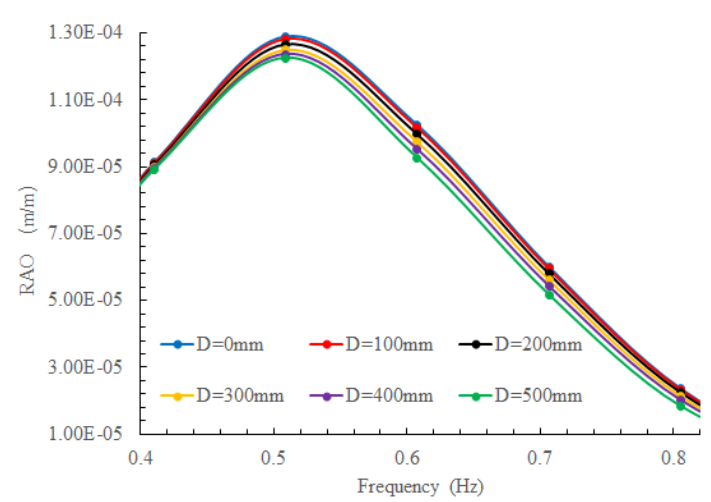

(a) Surge direction

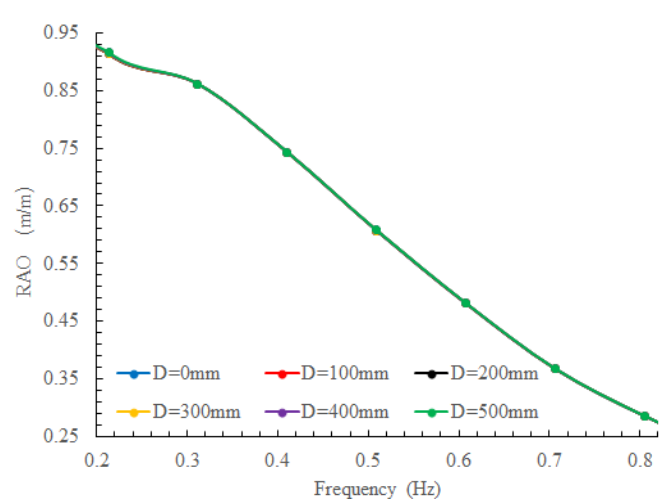

(b) Sway direction 


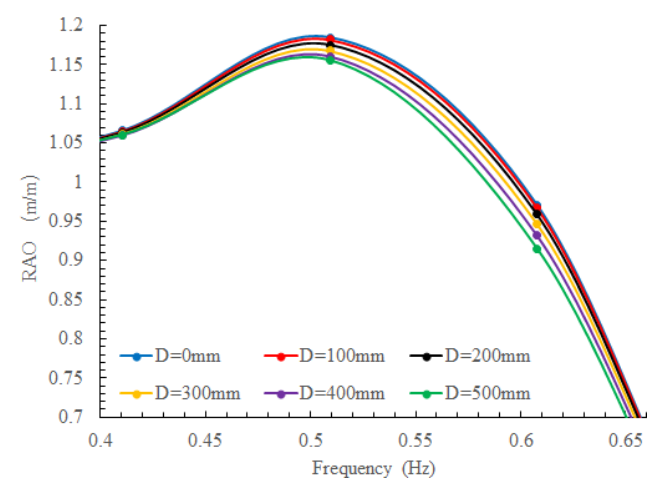

(c) Heave direction

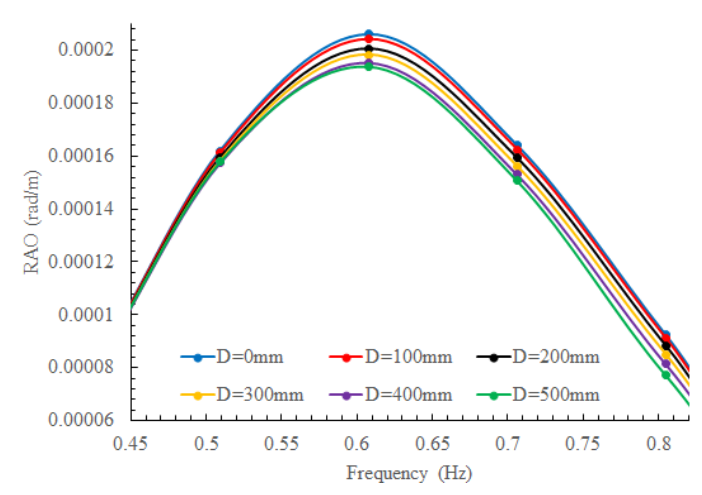

(e) Pitch direction

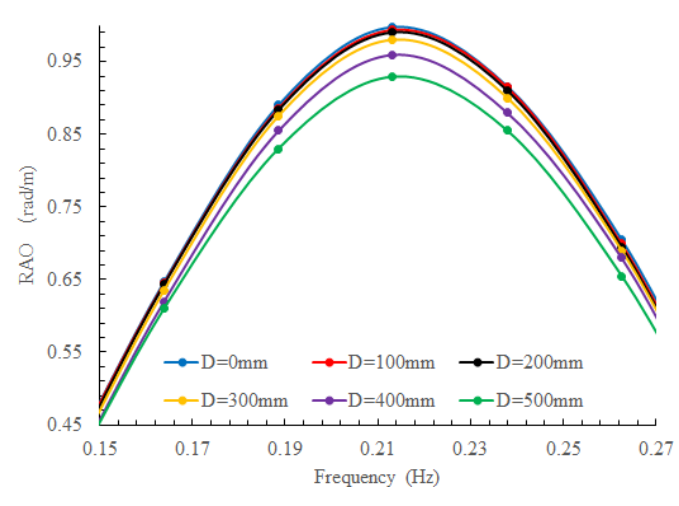

(d) Roll direction

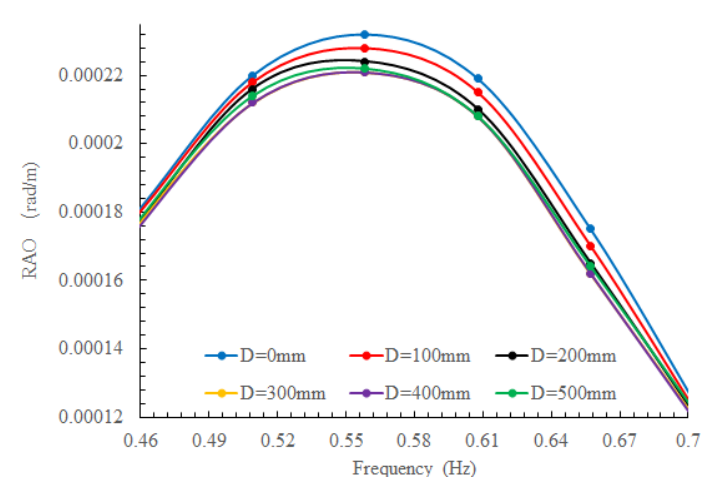

(f) Yaw direction

From Figs. $5 \mathrm{c}$ and d, it is found that heave plates do significantly constrain the motions of the vessel in heave and roll directions. Moreover, the larger the size of the heave plates, the more the motions are reduced. In contrast to the motion reduction in heave and roll directions, Fig.5e indicates that the vessel's pitch motion is less affected by the heave plates although the larger contribution of bigger heave plates to pitch motion reduction at corresponding frequencies can still be observed from the curves. This is because, as mentioned at the beginning of Section 2.2, the sea waves that are considered in the calculations are beam sea waves that approach the vessel from broadside. It is well known that beam sea waves have little influence on the pitch motion of the vessel. Such a phenomenon fully demonstrates that the CFD model developed in this paper is completely right and the its prediction to the vessel's motions is reliable. Such a conclusion is further proved by the RAOs shown in Figs.5a, b and f. Since the beam sea waves approach the vessel from broadside, significant sway motions of the vessel are clearly observed from Fig.5b. However, as shown in Fig.5b, the vessel's sway motion is irrelative to the change of the size of the heave plates. This is because the sway direction damping of the system is nearly not influenced by the heave plates. Likewise, the change in the size of heave plates does not change the system's damping either in surge and yaw directions. Therefore, the influences of the heave plates on the RAOs in these two directions are also very small and ignorable, as shown in Figs.5a and $\mathrm{f}$. 
Part II - is to investigate how the underwater distance of the heave plates affect the motions of the vessel under different wave conditions. Different from the investigations conducted in Part I, the underwater distance of the heave plates is variable, while the size of the plates is fixed. To ease understanding, the RAOs of the vessel, obtained when the diameter of the heave plates is $0.5 \mathrm{~m}$ whilst their underwater distance is respectively 0.5, 0.7, 1.0, 1.2 and $1.5 \mathrm{~m}$, are shown in Fig.6. Considering the motions of the vessel in the directions of heave, roll and pitch are more important to the safe operation of the crew transfer vessel, only the RAOs in these three directions are shown in Fig.6 in order to keep a concise context of the paper.

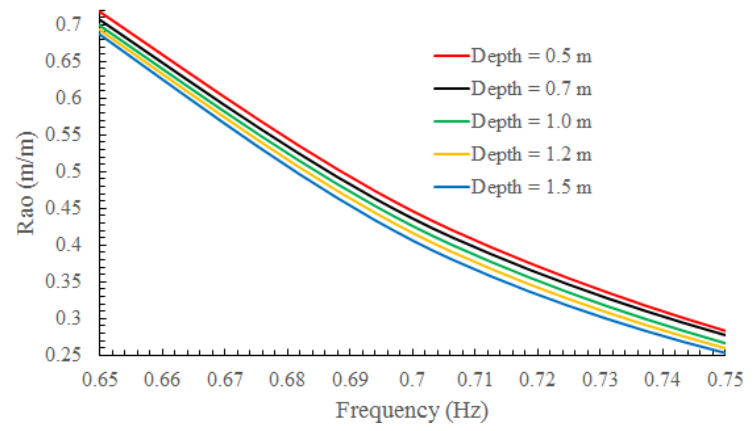

(a) Heave direction

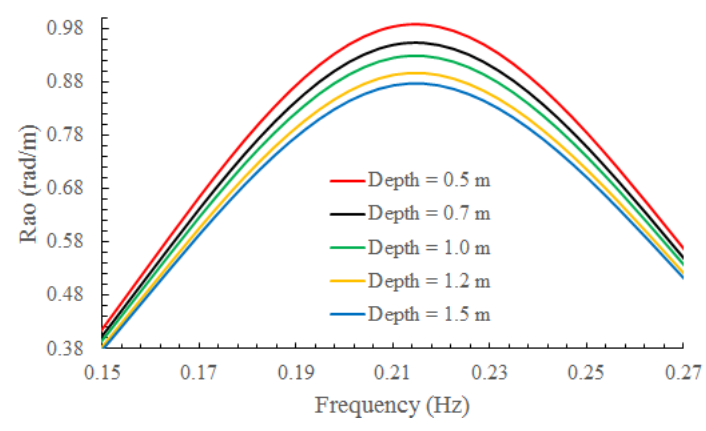

(b) Roll direction

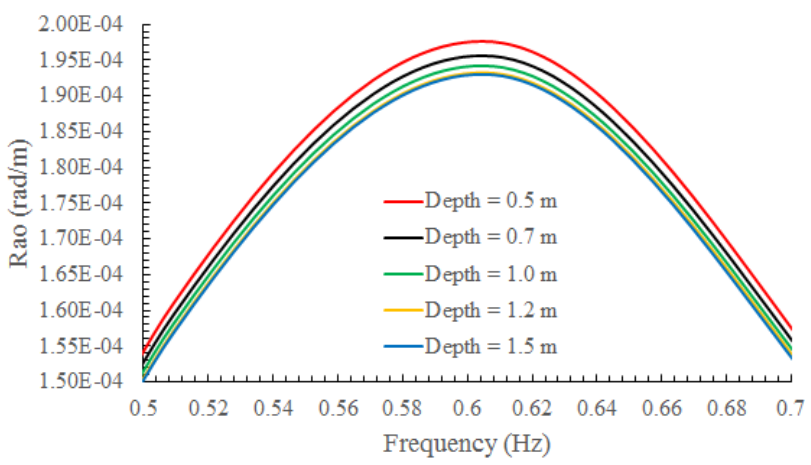

(c) Pitch direction

Fig.6 Influence of the underwater distance of heave plates on the motions of crew transfer vessel

From Fig.6, it is found that the underwater distance of heave plates does have a significant influence on the motion stability of the vessel, i.e. the deeper the heave plates are placed, the more the motions of the vessel are constrained in all these three directions. This is because according to wave theory, the energy of sea wave will decay gradually with the increase of the distance away from free water surface. Consequently, the sea waves will have less influence on the heave plates when they are placed at deeper underwater distance. In the meantime, the hydrodynamic damping of the system will increase with the increase of the underwater distance of the heave plates. Therefore, more motion reduction is observed when the heave plates are placed at deeper water distance. But as observed from Fig.5, the RAO values shown in Fig.6c are much smaller than those in Figs.6a and b, because the 
beam sea waves have significant influences on the heave and roll motions of the vessel, whilst have less influence on the vessel's pitch motion.

\section{Experimental Research}

249

250

\subsection{Testing facilities and data processing method}

In order to verify the findings in the aforementioned numerical research and investigate the actual contribution of the heave plates to stabilizing the motion of the crew transfer vessel, experimental research was further conducted with the aid of the marine testing facilities in the hydro-laboratory of Newcastle University. The towing tank for conducting motion tests, the 'Qualisys' system for data acquisition, and the physical model of the crew transfer vessel equipped with four extension legs and heave plates, are shown in Fig.7. The geometries of the physical model of the vessel and the wave conditions simulated in the experimental tests are listed in Table 3.

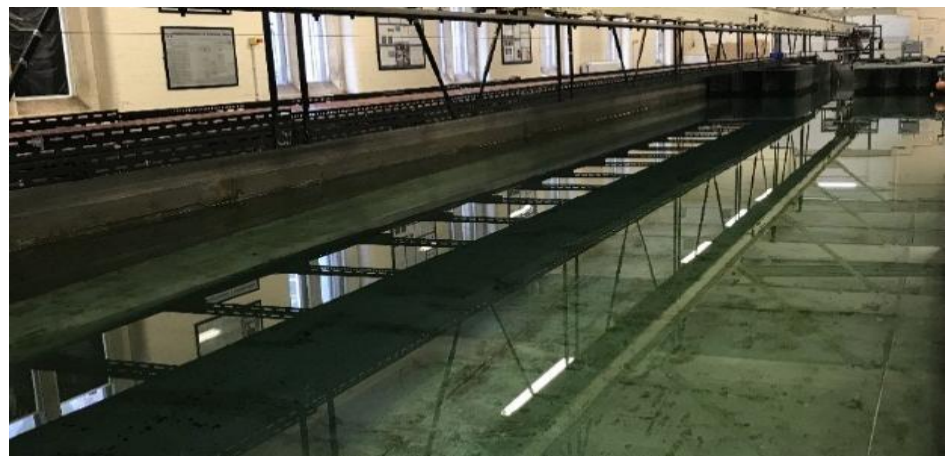

(a) Towing tank for conducting motion tests

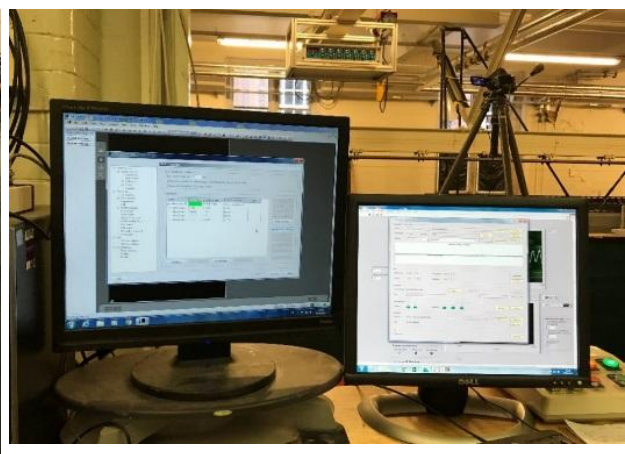

(b) Qualisys system for data acquisition

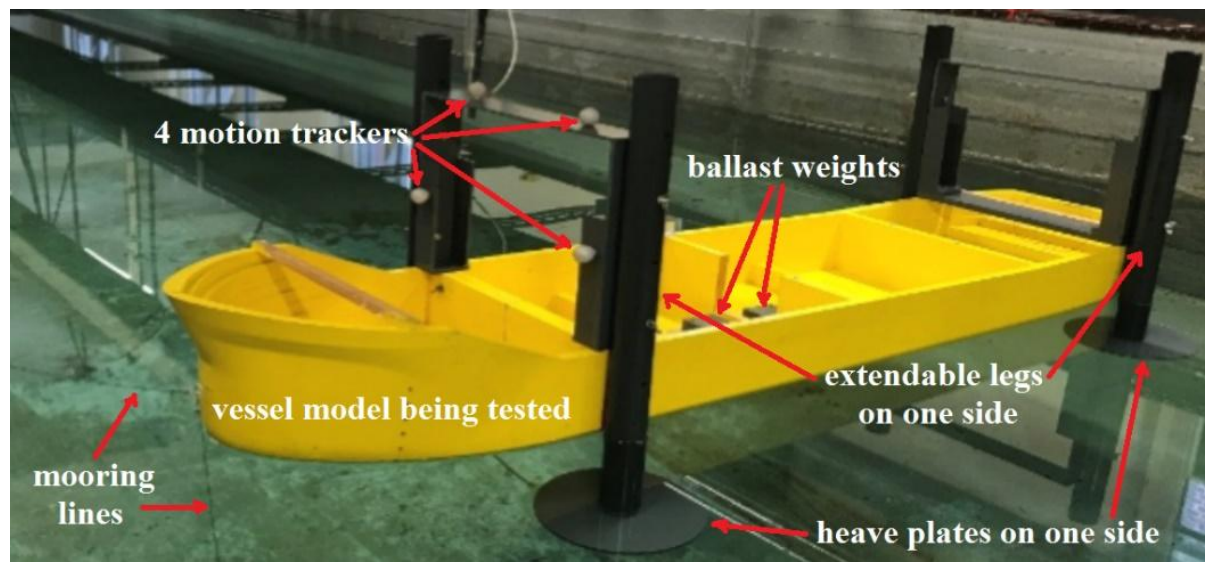

(c) Physical model of the vessel being tested

Fig.7 Testing facilities in the hydro-laboratory of Newcastle University 
Table 3. Geometries of the physical model and sea waves being simulated in the tests

\begin{tabular}{l|c|l|l}
\hline \multicolumn{2}{c|}{ Geometries of the physical model } & \multicolumn{2}{c}{ Wave conditions simulated in the tests } \\
\hline Length & $2 \mathrm{~m}$ & Scenario 1 & Wave period $0.5 \mathrm{~s}$, wave height $0.12 \mathrm{~m}$ \\
\hline Beam & $0.5 \mathrm{~m}$ & Scenario 2 & Wave period $1.0 \mathrm{~s}$, wave height $0.12 \mathrm{~m}$ \\
\hline Draft & $0.1 \mathrm{~m}$ & Scenario 3 & Wave period $1.5 \mathrm{~s}$, wave height $0.12 \mathrm{~m}$ \\
\hline Freeboard & $0.06 \mathrm{~m}$ & Scenario 4 & Wave period $2.0 \mathrm{~s}$, wave height $0.12 \mathrm{~m}$ \\
\hline
\end{tabular}

264

265

266

267

268

269

270

271

272

273

274

275

276

277

278

279

280

Similarly, beam sea wave conditions are considered in the experimental tests. In each scenario of wave condition, the motions of the physical model of the vessel in all six degree of freedom are tested when the underwater distance of the heave plates is $0.05,0.15,0.25$ and $0.35 \mathrm{~m}$ and their diameter is respectively $0,0.05,0.15,0.25$ and $0.35 \mathrm{~m}$. Accordingly, there are total 80 tests are conducted in the experimental research. Considering it is unlikely to show all testing results within the limited context of the paper and the motion stability of the vessel in heave, roll and pitch directions are more important to the safe operation of the crew transfer vessel, only the testing results in these three directions are discussed in the following. To ease understanding, the time waveforms of the vessel motions measured when the wave period $T$ is respectively $1.0 \mathrm{~s}$ and $1.5 \mathrm{~s}$ are illustrated in Fig. 8 as illustrative examples.

From Fig.8, it is seen that regardless of the wave period, the vessel's motions in heave, roll and pitch directions are significantly reduced after the heave plates are applied to the vessel. Moreover, the larger the size of the heave plates, the more the motion are reduced. But as expected, the pitch motions of the vessel are generally much smaller than its roll motions as the waves in the tests are beam sea waves.

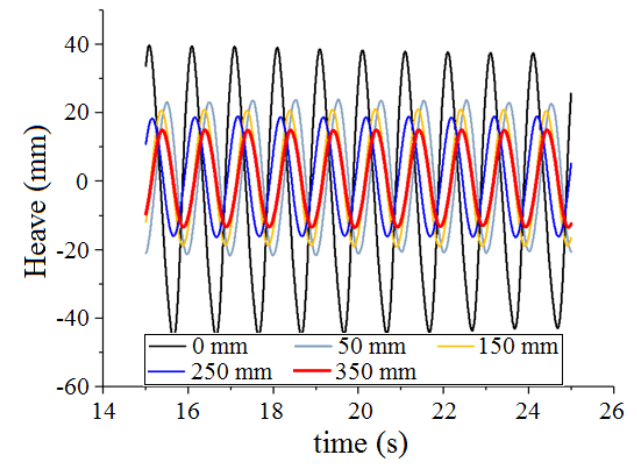

(a) Heave direction, $T=1.0 \mathrm{~s}$

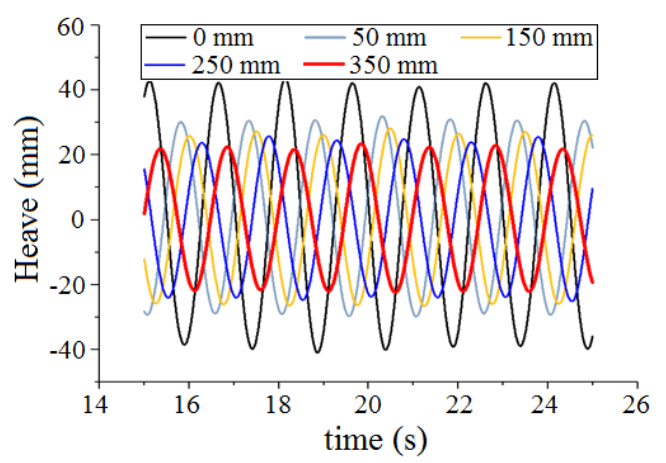

(b) Heave direction, $T=1.5 \mathrm{~s}$ 


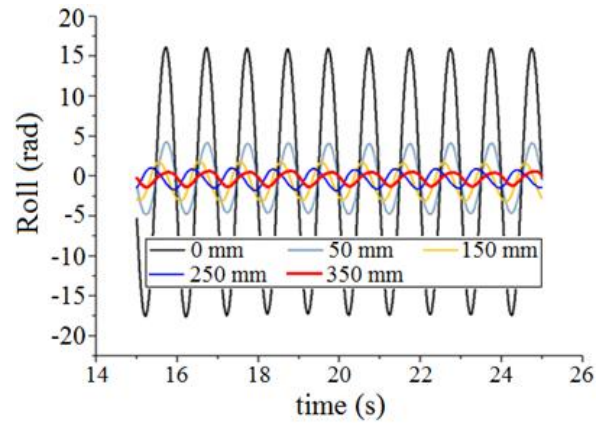

(c) Roll direction, $T=1.0 \mathrm{~s}$

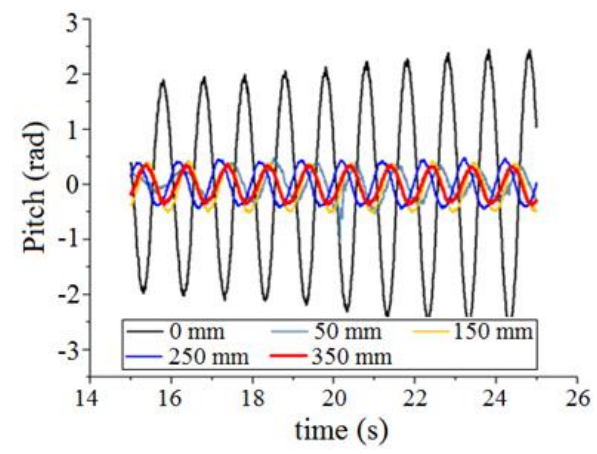

(e) Pitch direction, $T=1.0 \mathrm{~s}$

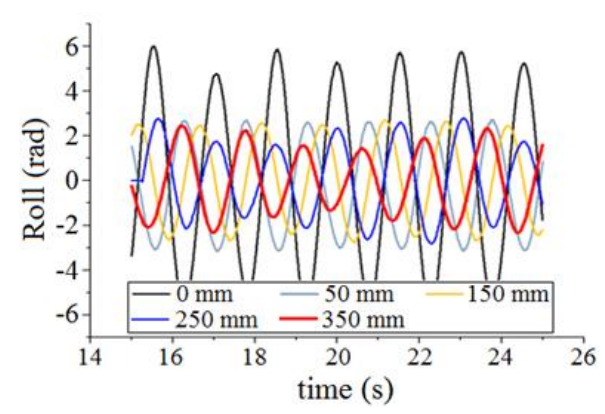

(d) Roll direction, $T=1.5 \mathrm{~s}$

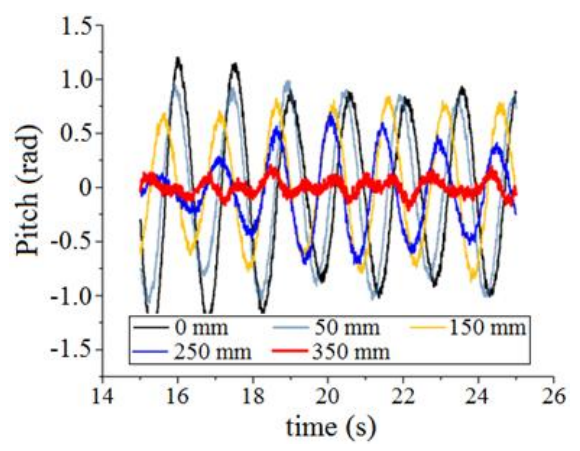

(f) Pitch direction, $T=1.5 \mathrm{~s}$

Fig.8 The measured motions of the physical model of the vessel

To facilitate motion assessment, the RAOs of the vessel in all these three directions are calculated. In theory, when a floating structure is excited by a regular wave with constant amplitude $\zeta_{a}$ and constant frequency $\omega$, its response will be an oscillation of the same frequency $\omega$ and with a constant amplitude $a\left(a \neq \zeta_{a}\right)$. Then, the RAO of the floating structure can be calculated by using equation

$$
\operatorname{RAO}(\omega)=\frac{a(\omega)}{\zeta_{a}(\omega)}
$$

where $\omega=\frac{2 \pi}{T}$ and $\zeta_{a}(\omega)$ are respectively the frequency and amplitude of exciting waves, $a(\omega)$ is the amplitude of the corresponding response of the floating structure.

However, it is noticed from Fig. 8 that in reality the practical response amplitude of the structure is not always constant over time due to various reasons (e.g. the interference of the waves returning from the end of the towing tank). In order to improve the accuracy of RAO calculations, a root-meansquare-value based method is often adopted in the practical calculation. Assume the measured elevation of the exciting wave is $\zeta_{a}(t)(t=0 \sim T)$ and the measured elevation of the structure response is $a(t)(t=0 \sim T)$, the RAO can be estimated by [15]

$$
\mathrm{RAO}=\sqrt{\frac{\int_{0}^{T}\left\{[a(t)-\bar{a}]^{2}\right\} d t}{\int_{0}^{T}\left\{\left[\zeta_{a}(t)-\overline{\zeta_{a}}\right]^{2}\right\} d t}}
$$

where $\overline{\zeta_{a}}$ and $\bar{a}$ are the mean values of $\zeta_{a}(t)$ and $a(t)$.

The calculation method described in (4) is simple in calculation and robust against noise. It is however unable to mitigate the negative influences of those sub- and higher orders of frequency 
components in the sea waves on the accuracy of RAO. For this reason, a new RAO assessment method is proposed in the following in order to assure the reliability of the RAO assessment result, i.e.

$$
\operatorname{RAO}(\omega)=\sqrt{\frac{s_{a}(\omega)}{s_{\zeta_{a}}(\omega)}}
$$

where $S_{a}(\omega)$ and $S_{\zeta_{a}}(\omega)$ are the values of the power spectral density of signals $a(t)$ and $\zeta_{a}(t)$ at the fundamental frequency $\omega$ of the exciting waves. They are calculated by

$$
\left\{\begin{array}{l}
S_{a}(\omega)=\int_{-\infty}^{\infty} R_{a, a}(\tau) e^{-i \omega \tau} d \tau \\
S_{\zeta_{a}}(\omega)=\int_{-\infty}^{\infty} R_{\zeta_{a}, \zeta_{a}}(\tau) e^{-i \omega \tau} d \tau
\end{array}\right.
$$

where $i=\sqrt{-1} . R_{a, a}(\tau)$ and $R_{\zeta_{a}, \zeta_{a}}(\tau)$ are the autocorrelation of the measured signals $a(t)$ and $\zeta_{a}(t)$ at the time moment of $\tau$. They can be readily calculated using the following equations

$$
\left\{\begin{array}{l}
R_{a, a}(\tau)=\boldsymbol{E}[a(t) a(t+\tau)]=\lim _{T \rightarrow \infty} \frac{1}{T} \int_{-T / 2}^{T / 2}[a(t) a(t+\tau)] d t \\
R_{\zeta_{a}, \zeta_{a}}(\tau)=\boldsymbol{E}\left[\zeta_{a}(t) \zeta_{a}(t+\tau)\right]=\lim _{T \rightarrow \infty} \frac{1}{T} \int_{-T / 2}^{T / 2}\left[\zeta_{a}(t) \zeta_{a}(t+\tau)\right] d t
\end{array}\right.
$$

where $\boldsymbol{E}[\cdot]$ denotes expected value.

From (5)-(7), it is seen that the value of the calculated RAO is only dependant on the values of the power spectral density of the exciting wave $\zeta_{a}(t)$ and response $a(t)$ at fundamental frequency $\omega$. It is not affected by the other frequency components $n \cdot \omega(n>0)$ contained in sea waves. Therefore, the RAO assessed by using the power-spectral-density based method should be more accurate and reliable than those obtained by using the conventional root-mean-square-value based method.

\subsection{Experimental results}

In order to verify the findings in the numerical research, influences of both the size and the underwater distance of the heave plates on the motions of the crew transfer vessel are investigated in the following. The measured wave and vessel response data are processed by using the method proposed in section 3.1. The resultant RAOs under different wave conditions are shown in Figs.9 and 10. In order to keep a concise context of the paper, only the RAO assessment results obtained when the underwater distance is 0.05 and $0.15 \mathrm{~m}$ are illustrated in Fig.9, and only the RAOs obtained when the diameter of the heave plates is $0.4 \mathrm{~m}$ are shown in Fig. 10 . 


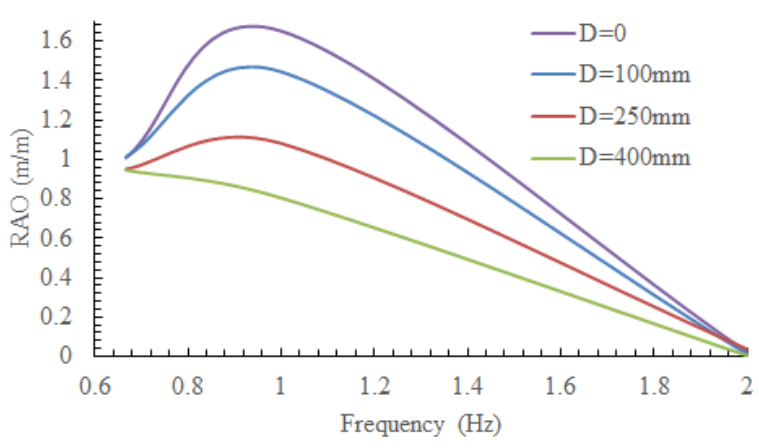

(a) Heave direction, underwater distance is 0.05 $\mathrm{m}$

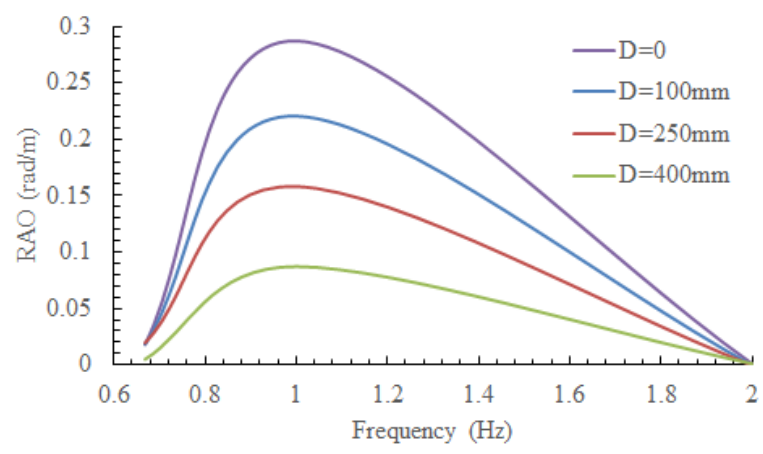

(c) Roll direction, underwater distance is $0.05 \mathrm{~m}$

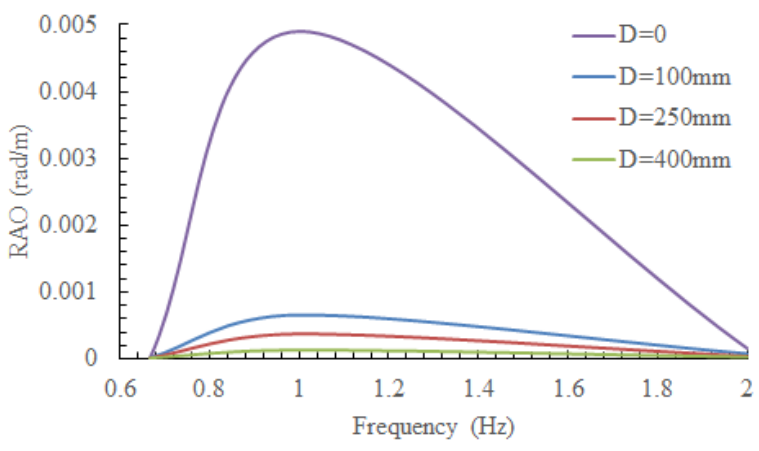

(e) Pitch direction, underwater distance is 0.05 $\mathrm{m}$

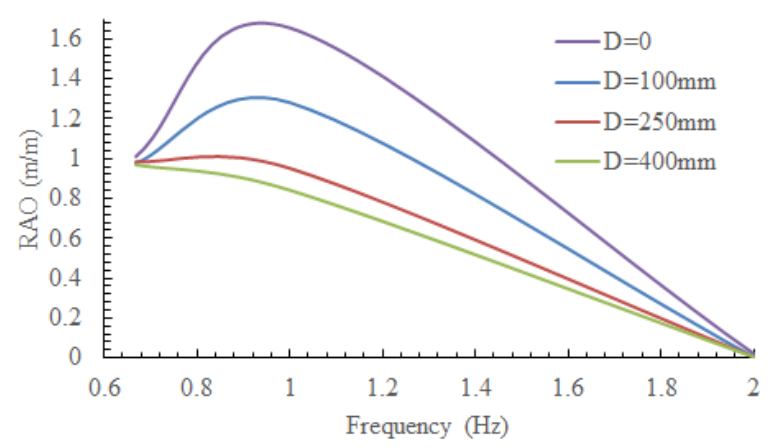

(b) Heave direction, underwater distance is 0.15 $\mathrm{m}$

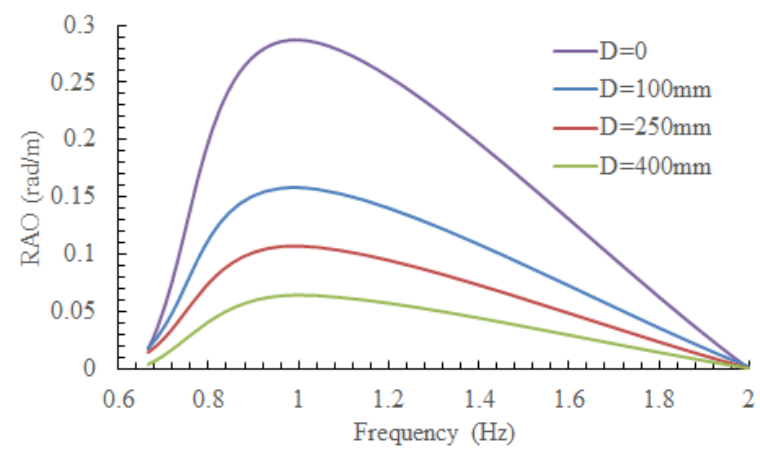

(d) Roll direction, underwater distance is $0.15 \mathrm{~m}$

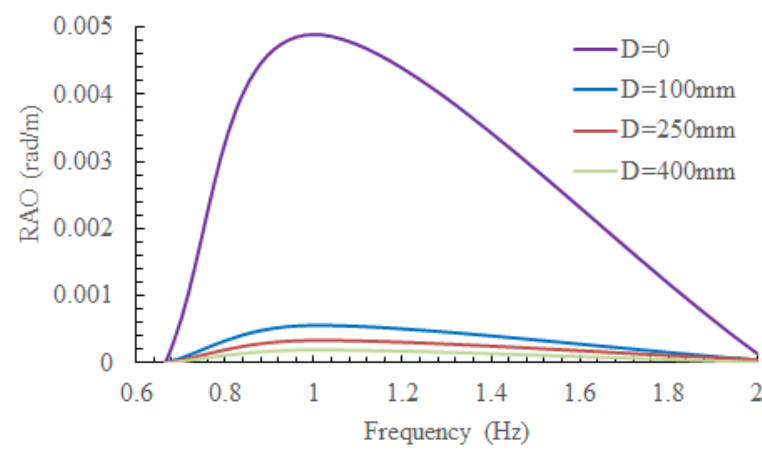

(f) Pitch direction, underwater distance is $0.15 \mathrm{~m}$

Fig.9 Influences of the size of heave plates at underwater distances $0.05 \mathrm{~m}$ and $0.15 \mathrm{~m}$

From Fig.9, it is seen that regardless of the underwater distance that the heave plates are placed, the motions of the vessel in heave, roll and pitch are significantly reduced after the heave plates are applied to the vessel. Moreover, the larger the size of the heave plates, the more the motions of the vessel are constrained, particularly in the resonant frequency region of $0.6-2 \mathrm{~Hz}$. Such a phenomenon is completely in consistence with the findings in the numerical research. In addition, through comparing the RAO curves corresponding to different sizes of heave plates, it is noticed that the application of the heave plates more or less decreases the values of the natural frequencies of the vessel. Moreover, the larger the size of the heave plates, the more the natural frequency of the vessel decreases. This is because the heave plates not only increase the physical mass of the vessel but also 
increase the added mass of the vessel. As a consequence, the natural frequency of the whole 'vessel + heave plates' system is correspondingly decreased. Additionally, the comparison of Fig.5 and Fig.9 interestingly indicates that the effect of heave plate on the vessel's motion stability can be more clearly observed from the experimental results in Fig.9 rather than from the numerical simulation results in Fig.5. This is because water is a viscous fluid. The viscosity of water will amplify the motion reduction effect of the heave plates. However, the viscosity of water is neglected in the CFD calculations to ensure the differential hydrodynamics equations to be tractable.

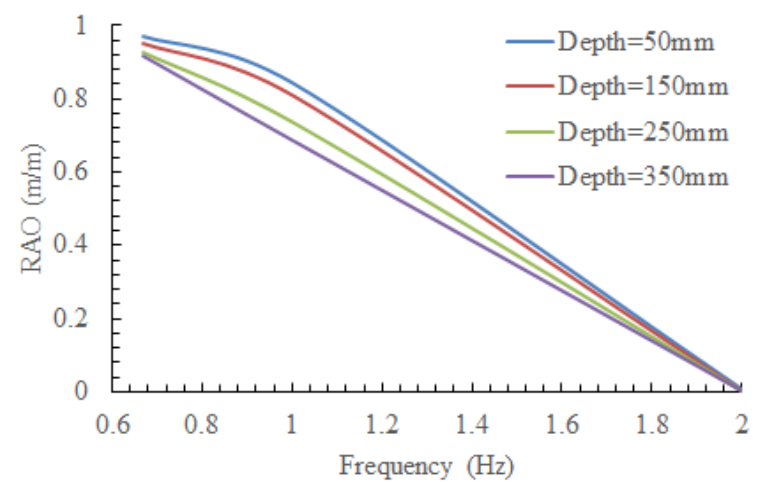

(a) Heave direction

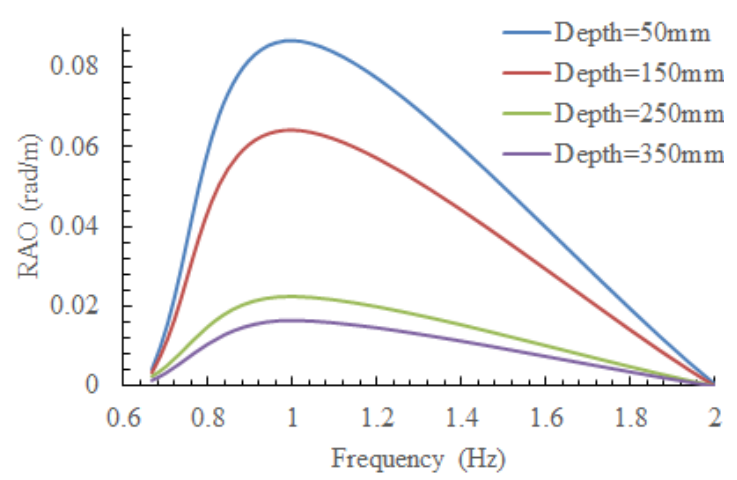

(b) Roll direction

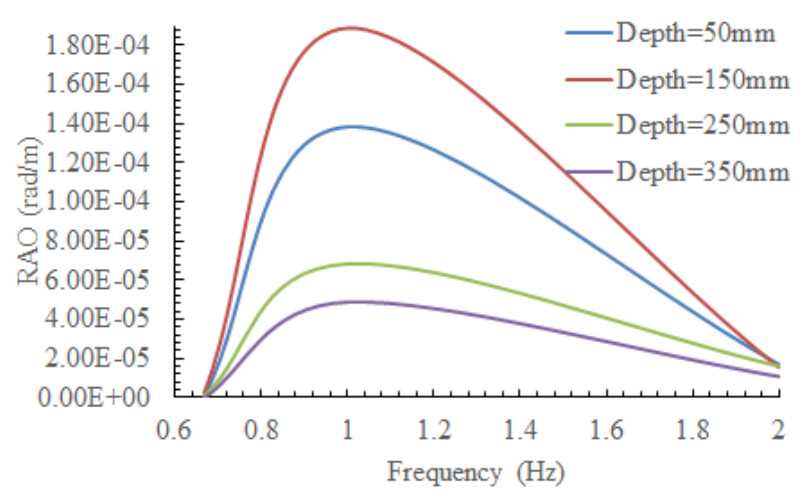

(c) Pitch direction

Fig.10 Influences of the underwater distance of heave plates

From Fig.10, it is found that the distance that the heave plates are placed under water surface does have a significant influence as well on the motions of the vessel. Moreover, the deeper that the heave plates are placed under water surface, the more the motion of the vessel can be constrained by the heave plates. Such a phenomenon agrees very well with those observed from the numerical simulation results shown in Fig.6. Additionally, as predicted in Fig.6, it is found from Fig.10 that the beam sea waves do have more significant influence on the vessel's heave and roll motions than on its pitch motion. 
Crew transfer vessels are playing a vital role in the operation and maintenance of offshore wind farms. However, the present crew transfer vessels have limited capability to provide safe transfer between the vessel and wind turbines. This significantly lowers the efficiency of offshore wind farm maintenance activities. In view of this, a cost-effective motion stabilization technique is studied in this paper by using both numerical simulation and experimental testing approaches. From the researches described above, three key conclusions can be drawn:

(1) Heave plate does show an outstanding capability in stabilizing the motions of offshore wind farm crew transfer vessel. Moreover, the larger the size of heave plates, the more the motions of the vessel will be constrained particularly in the resonant frequency region of the vessel;

(2) The installation of the heave plates also has influence on their motion stabilization effect. The deeper the heave plates are placed under water surface, the more the motions of the vessel will be reduced;

(3) The comparison of the numerical simulation and experimental testing results has disclosed that the viscosity of water can further amplify the motion stabilization effect of heave plates;

\section{Acknowledgement}

373 The work reported in this paper was supported by National Natural Science Foundation of 374 China with the reference numbers of 11772126 and 11632011, and State Key Laboratory of 375 Mechanical System and Vibration at Shanghai Jiaotong University with the reference number of MSV201702.

\section{References}

379 1. Global Wind Energy Council, Global wind statistics 2017, 14 ${ }^{\text {th }}$ February 2018.

380 2. UK Trade \& Investment, UK Offshore wind: Opportunities for trade and investment, 2015.

381 3. Dalgic, Y.; Lazakis, I.; Turan, O., Vessel charter rate estimation for offshore wind O\&M 382 activities, International Maritime Association of Mediterranean (IMAM 2013), October 14-17, 2013, A Coruna, Spain.

4. 4Coffshore, Wind farm service vessels (WFSVs) -An analysis of supply and demand, January 2015.

5. Vroon Offshore Services and Ampelmann join forces for Arkona wind farm project, January 15, 2018. https://www.ampelmann.nl/news/vroon-offshore-services-and-ampelmann-join-forces-forarkona-wind-farm-project. Accessed on 28 February 2018. 
6. Tavner, P.J.; Xiang, J.P.; Spinato, F., Reliability analysis for wind turbines. Wind Energy 2006, 10(1), 1-18.

7. Ribrant, J.; Bertling, L., Survey of failures in wind power systems with focus on Swedish wind power plants during 1997-2005. IEEE Transactions on Energy Conversion 2007, 22(1), 167-173.

8. Feng, Y.; Tavner, P.J.; Long, H., Early experience with UK round 1 offshore wind farms. Proceedings of Institution of Civil Engineers - Energy 2010, 163(NE4), 167-181.

9. Tavner, P.J., Offshore wind turbines - Reliability, availability and maintenance. The Institution of Engineering and Technology, 2012.

10. Tzeng, C.Y.; Wu, C.Y., On the design and analysis of ship stabilizing fin controller. Journal of Marine Science and Technology 2000, 8(2), 117-124.

11. Perez, T., Ship motion control. Springer-Verlag, London, 2005.

12. Cavalletti, M.; Ippoliti, G.; Longhi, S., Adaptive nonlinear control for vessel roll stabilization. IFAC Proceedings Volumes 2007, 40(17), 44-49.

13. Tao, L.; Cai, S., Heave motion suppression of a spar with a heave plate. Ocean Engineering 2004, 31, 669-692.

14. Subbulakshmi, A.; Sundaravadivelu, R., Heave damping of spar platform for offshore wind turbine with heave plate. Ocean Engineering 2016, 12, 24-36.

15. Wang, J., Research on the innovative techniques to stabilising crew boat in offshore wind farm. MSc Dissertation, Newcastle University, 2017. 


\title{
Research on a Cost-effective Measure Dedicated to
}

\section{Stabilizing Offshore Wind Farm Crew Transfer Vessels}

\author{
Wenxian Yang ${ }^{1}$, Wenye Tian ${ }^{1}$, Kexiang Wei ${ }^{2}$, Zhike Peng ${ }^{3}$, Zhonghua Huang ${ }^{2}$ \\ ${ }^{1}$ School of Engineering, Newcastle University, Newcastle upon Tyne NE1 7RU, UK \\ ${ }^{2}$ Hunan Province Cooperative Innovation Centre for Wind Power Equipment and Energy Conversion, \\ Hunan Institute of Engineering, Xiangtan 411104, China \\ ${ }^{3}$ State Key Laboratory of Mechanical System and Vibration, Shanghai Jiaotong University, Shanghai \\ 200240, China
}

\begin{abstract}
The rapidly growing offshore wind industry is calling for more crew transfer vessels to deliver increasing number of minor maintenance tasks as about $75 \%$ of onshore wind turbine failures are related to the minor errors occurring in the electrical and power electronic systems of the turbines. The situation in offshore wind farms may be worse due to the wet, salty and corrosive air in offshore environments. Due to the limitations of small hull and deck spaces, there is difficulty to apply the proven motion stabilization techniques to wind farm crew transfer vessels. Consequently, the present crew transfer vessels have limited capability in providing safe transfer between the vessel and wind turbines, particularly in rough sea waves. To tackle this issue, a new motion stabilization technique is studied in this paper by using both numerical analysis and experimental testing approaches. Through investigating the vessel's motions under different wave conditions before and after applying the proposed technique, it is found that the heave, roll and pitch motions of the vessel, especially in its resonant frequency regions, have been successfully constrained after applying the proposed stabilizing technique. Moreover, the amount of motion reduction can be further improved through optimizing the size of stabilizers and their underwater distance.
\end{abstract}

\section{Keywords}

Offshore wind farm; crew transfer vessel; motion stability; response amplitude operator 


\section{Background}

Together with solar, hydro-power, geothermal and other renewable energy forms as well as the emergence of sophisticated grid management and affordable energy storage, wind is playing an increasingly vital role in developing a fossil-free power society. According to the annual market report released by the Global Wind Energy Council (GWEC), the annual installed wind capacity is 52,573 MW in 2017. This brings the global total installed wind capacity to 539,581 MW, of which $3.5 \%$ is from offshore [1]. There is no doubt that the present offshore wind industry is in infancy and its market share is still 'tiny'. However, exploiting offshore wind resources has become an irreversible tendency in the wind industry attributing to the stable and high wind speed offshore and the absence of land use issues in open sea. According to the recent survey by the GWEC, the total installed offshore wind capacity has reached 18,814 MW by the end of 2017, versus 14,483 MW in 2016 and $12,167 \mathrm{MW}$ in 2015 [1]. It is sure that such a growing tendency will continue in the following years. Take the UK offshore wind market as an example, the installed offshore wind capacity is predicted to increase from the present $5.07 \mathrm{GW}$ to $10 \mathrm{GW}$ by 2020 , which will attract $£ 16-21$ bn more investment into the UK market [2]. That means that there will be thousands of wind turbines scattering in a very large sea area. Due to the harsh offshore environment and limited maintenance window of offshore wind farms, how to access so many wind turbines and ensure their safe operation over the whole service life has become a challenging and difficult issue that must be urgently solved today.

At present, helicopter and wind farm service vessel (WFSV) are two major tools used for accessing offshore wind farms and the latter is comparatively cheap in practical application [3]. To date, there have been more than 250 WFSVs are serving in the UK offshore wind market and the fleet is still growing to meet the expanding market of offshore wind [4]. Among these vessels, some are large in size and designed for conducting major maintenance tasks. They are equipped with powerful cranes (for lifting large and heavy wind turbine components to heights) and advanced wave compensation system (for providing safe transfer between the vessel and wind turbines, such as the A400 gangway system developed by Vroon Offshore Services and Ampelmann [5]). But in contrast to these large maintenance vessels, more WFSWs are crew transfer vessels that are small in size and designed for transferring maintenance crews and delivering minor maintenance tasks. Moreover, it is believed that a larger number of vessels of the kind will be demanded by future offshore wind farms. This is because the electrical and power electronic components in wind turbines are more vulnerable to failure than their mechanical counterparts, whilst the failures of these kinds of systems can be fixed via minor maintenance. For example, the survey has shown that about $75 \%$ of onshore wind turbine failures are related to the minor errors occurring in the electrical and power electronic control systems of the turbines [6,7]. There is no doubt that the wet, salty and corrosive air in offshore environments will worsen the situation in offshore wind farms [8,9]. The crew transfer vessels are usually $14-20 \mathrm{~m}$ long and are allowed to operate only when the significant wave height is less than $1.8 \mathrm{~m}$. Due to the 
small hull and limited deck spaces, they are not equipped with proven motion stabilization and wave compensation system. Consequently, their seakeeping performance is relatively poor particularly in rough waves. Therefore, they are unable to provide sufficiently safe transfer between the vessel and wind turbines. However, the safe transfer between the vessel and wind turbines is crucial in the operation and maintenance of offshore wind turbines as unsafe transfer would place the maintenance crew at a high risk of injury. It can also cause serious damage to the wind turbines, as illustrated in Fig.1.

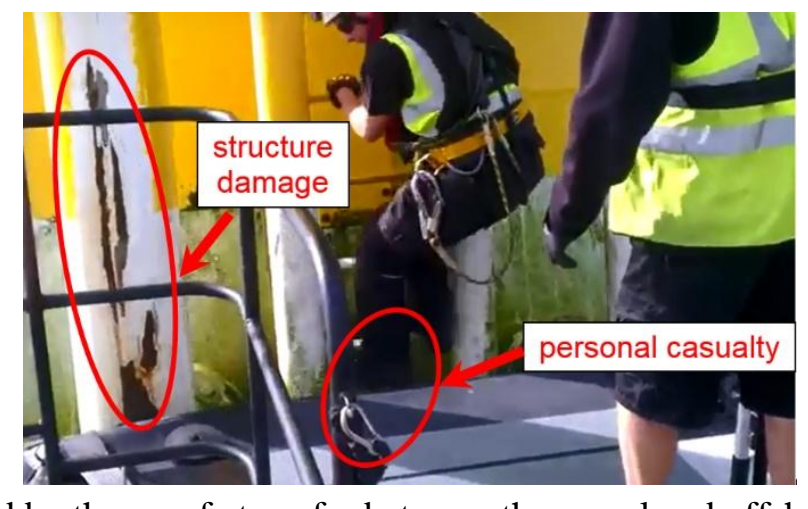

The unsafe transfer between the crew transfer vessel and wind turbines is largely due to the poor seakeeping performance of the vessel (i.e. unstable motion of the vessel in rough waves). However, the proven vessel motion stabilization techniques (e.g. gyro stabilizer, active fin stabilizer, anti-rolling tanks, active ballast system, etc.) that have been reviewed in [10-12] and popularly used in large vessels are not applicable to crew transfer vessels due to the small hull and limited deck spaces of the vessels. In order to address this issue, many techniques and methods, either simple or complex, have been attempted in the past years. Among these techniques, two most popular ones are illustrated in Fig.2.

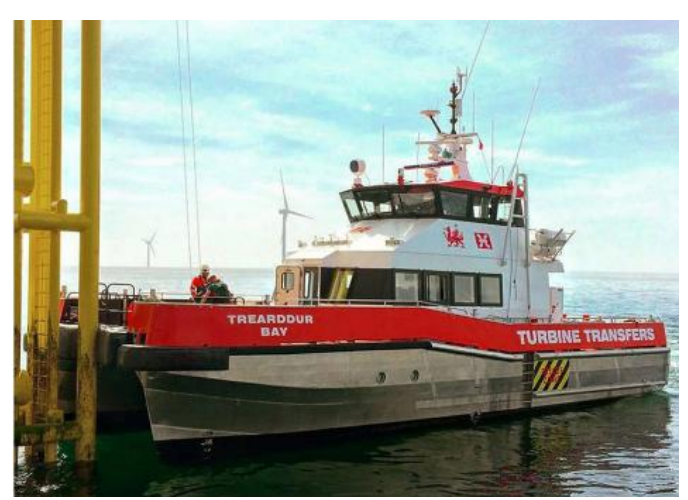

(a) Rubber bumper system

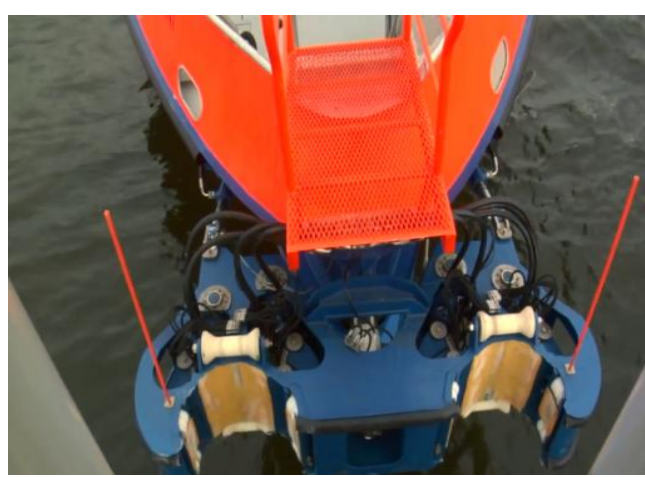

(b) Hydraulic gripper system

Fig.2 Two most popular techniques for achieving safe transfer between crew transfer vessels and offshore wind turbines 
(1) Rubber bumper system - realizes access by creating frictional contact between the vessel and the ladder of offshore wind turbines. The rubber bumper on the vessel bow will form the contact point. To limit the vessel's motions at the point of contact, one has to keep the thrusters running over the whole period to push the boat against the turbine to create sufficient friction. Such a method is limited by wave conditions, e.g. the vessel may lose its contact with the turbine when wave condition is rough. That will make the safe transfer between the vessel and wind turbines no longer possible. Moreover, the thrusters are kept running in the whole period, which makes the transfer uneconomical on fuel. In addition, the huge pushing force by the thrusters may cause potential damage to the structures of wind turbines, see Fig.1. Where, the paint on wind turbine structure was seriously damaged by the vessel. As a consequence of the loss of paints, the turbine structure is exposed in the sea water and/or wet air. That will cause corrosion of the structure if not being repaired in time;

(2) Hydraulic gripper system - enables the vessel to grip turbine ladder using two hydraulic grippers. It reduces the friction-induced damage to turbine structure via rollers. In comparison of the aforementioned rubber bumper system, it does not request the thrusters to keep running after the vessel is locked on turbine ladder by hydraulic grippers. Therefore, it allows fuel saving. However, due to the almost fixed contact point the deck of the vessel may be flooded when experiencing rough waves, making transfer not safe anymore.

In order to improve the safe transfer between the crew transfer vessel and offshore wind turbines, a new motion stabilization technique is numerically and experimentally studied in this paper with the aid of software ANSYS AQWA and the marine testing facilities in the hydro-laboratory of Newcastle University. This new vessel stabilizing technique is proposed with the inspiration of the great contribution of heave plate to suppressing the heave motion of floating structures [13,14]. The major research interest of this paper is to investigate the contributions of heave plates to the motion stability of the vessel, particularly in heave, roll and pitch directions that are critical to the safety of transfer. The influences of the size of heave plates and their underwater distance on the motions of the vessel are investigated under various wave conditions by using both numerical analysis and experimental testing approaches. The investigation results have shown that the proposed motion stabilization technique does effectively constrain the motions of the vessel in all six degree of freedom. Moreover, the proposed technique is cheap and easy to deploy on the crew transfer vessels in contrast to those existing proven motion stabilization measures.

\section{Numerical Research}

\subsection{Numerical model}

127 In order to facilitate the numerical research, firstly a computational fluid dynamics (CFD) model of 128 the offshore wind farm crew transfer vessels was developed in ANSYS AQWA, as shown in Fig.3. It 
is $5.61 \mathrm{~m}$ long, $1.65 \mathrm{~m}$ wide, and $0.7 \mathrm{~m}$ high. Its draft is $0.3 \mathrm{~m}$ and it is assumed to operate in $30 \mathrm{~m}$ depth water. Four extendable 'legs' are designed in the model in order to place the heave plates at different underwater distances. A point mass, $m=2330.90 \mathrm{~kg}$, was defined to indicate the mass and the centre of gravity of the vessel. The moment of inertia of the model is estimated by

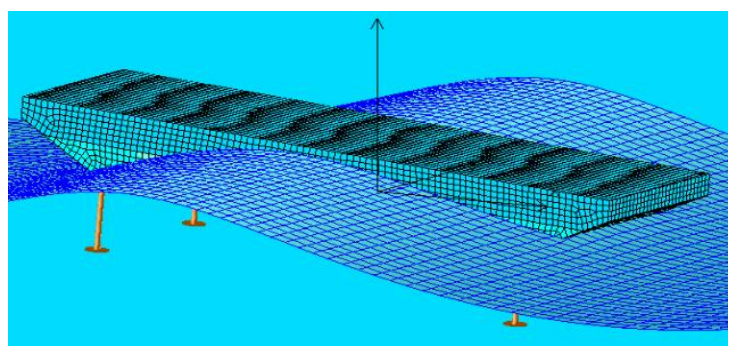

Fig.3 Numerical model of the crew transfer vessel when wave direction angle is 0 degree

$$
I_{i, j}= \begin{cases}m \times r_{i, j}^{2} & \text { when } i=j \\ 0 & \text { when } i \neq j\end{cases}
$$

where $i, j=1,2$ and 3. $r_{i, j}$ refers to the radius of gyration in different directions. Given the length and beam of the vessel are respectively $L$ and $B$, then the value of $r_{i, j}$ can be estimated by

$$
\left\{\begin{array}{l}
r_{1,1}=0.34 \times L \\
r_{2,2}=0.25 \times B \\
r_{3,3}=0.26 \times B
\end{array}\right.
$$

Using (1) and (2), it can be readily obtained that $I_{1,1}=8415 \mathrm{~kg} \cdot \mathrm{m}^{2}, I_{2,2}=392 \mathrm{~kg} \cdot \mathrm{m}^{2}$, and $I_{3,3}=431 \mathrm{~kg} \cdot \mathrm{m}^{2}$, respectively.

In order to obtain a reliable prediction to the motion stabilization effect of the proposed technique, the meshing method of the CFD model is carefully considered before starting the numerical calculations. The CFD model was discretized by using different sizes of elements, and then the ideal meshing method can be readily identified from convergence curves. For example, the convergence curve of the vessel's Response Amplitude Operator (RAO) in pitch direction obtained at wave frequency of $0.5 \mathrm{~Hz}$ is shown in Fig.4. Herein, it is essential to note that the RAO is a transfer function used to reflect the effect of sea waves on the motion of a floating structure.

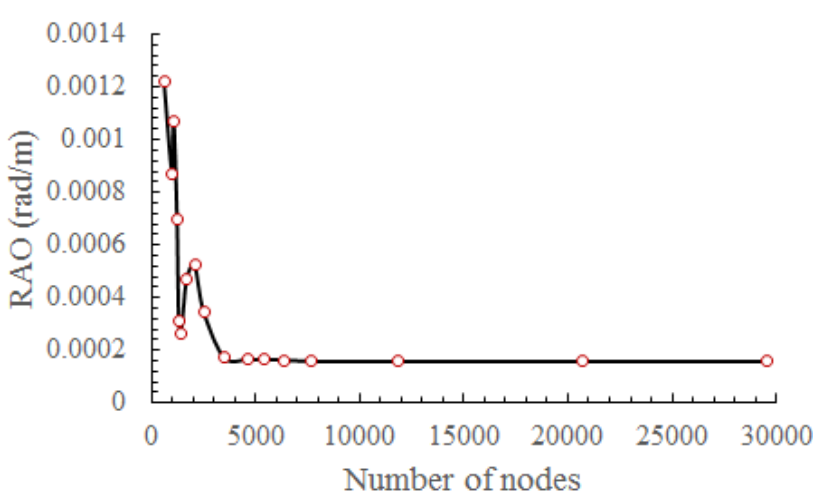

Fig.4 Convergence of the pitch motion of the vessel against different number of nodes 
From Fig.4, it is seen that with the increase of the number of nodes (i.e. decreasing size of meshing elements), the calculated value of the pitch RAO shows a general decreasing tendency with the increasing number of nodes. The value of the RAO finally reaches a saturated value of 0.000157 $\mathrm{rad} / \mathrm{m}$ when the number of nodes is 20,700 , which corresponds to the maximum element size of 0.06 $\mathrm{m}$. This suggests that a reliable prediction to the vessel's motions can be achieved from the numerical CFD calculations as long as the maximum element size is smaller than $0.06 \mathrm{~m}$. Therefore, the maximum element size is set to be $0.05 \mathrm{~m}$ in the following calculations in order to fully guarantee the reliability of the research conclusions drawn from the following numerical investigations. Accordingly, the corresponding value of defeaturing tolerance was set to be 0.025 in the following numerical calculations as the defeaturing tolerance must be two times smaller than the maximum element size. The meshing details are listed in Table 1. It is worth noting that the model meshing in this research was implemented only on the surface of the model as the 'vessel' is a shell structure. Therefore, only the maximum element size is needed to define in the meshing processing. The actual size and the type of individual meshes will be automatically determined by the software based on the local changes of the model geometries and waves.

Table 1. Meshing details

\begin{tabular}{c|c|c|c|c}
\hline Parameter & No. of nodes & No. of elements & $\begin{array}{c}\text { No. of diffracting } \\
\text { nodes }\end{array}$ & $\begin{array}{c}\text { No. of diffracting } \\
\text { elements }\end{array}$ \\
\hline Value & 29,556 & 29,100 & 13,165 & 12,967 \\
\hline
\end{tabular}

170

Table 2. Software analysis settings

\begin{tabular}{l|c}
\hline Parallel Processing & Program Controlled \\
\hline Generate Wave Grid Pressures & Yes \\
\hline Wave Grid Size Factor & 2 \\
\hline Ignore Modelling Rule Violations & Yes \\
\hline Calculate Extreme Low/High Frequencies & Yes \\
\hline Calculate Drift Coefficients & Yes \\
\hline Include Multi-Directional Wave Interaction & Yes \\
\hline Near Field Solution & Program Controlled \\
\hline Linearized Morison Drag & Yes \\
\hline ASCII Hydrodynamic Database & No \\
\hline Example of Hydrodynamic Database & No \\
\hline
\end{tabular}

Before proceeding to numerical calculation, some software settings need to be defined as well in advance. The details of these settings are listed in Table 2 to enable the interested readers to repeat the calculations. 
calculation without giving any warning when an error occurs. In addition, the item 'Linearized Morison Drag' should be set to be 'Yes' too, allowing the heave plates and the 'vessel' to be simulated as one structure. Otherwise, the heave plates will not be simulated in the calculation if the status of this item was set to be 'No'. Moreover, only after the status of the item 'Linearized Morison Drag' is set to be 'Yes', an irregular wave spectrum (e.g. Pierson-Moskowitz) is allowed to be inserted into the hydrodynamic diffraction to activate the heave plates.

\subsection{CFD calculations}

With the completion of all the aforementioned settings, the motion stability of the vessel equipped with four heave plates are investigated under beam sea conditions (i.e. sea waves approach the vessel from broadside). In order to simplify the calculations, the same significant wave height 10 $\mathrm{m}$ was considered in all of the following calculations, whilst the wave frequency was designed to change gradually from 0 to $1 \mathrm{~Hz}$. As usual, the RAO is employed to assess the stability of the vessel in all six degree of freedom. The software will automatically calculate the vessel's RAOs in all directions upon the completion of CFD calculations. In order to investigate the influences of the size and underwater distance of the heave plates on the motions of the crew transfer vessel, five different underwater distances, i.e. $0.5,0.7,1.0,1.2$ and $1.5 \mathrm{~m}$, and six different diameters of the heave plates, i.e. $0,0.1,0.2,0.3,0.4$ and $0.5 \mathrm{~m}$, are considered in numerical investigations. Therefore, the whole numerical investigation consists of the following two parts:

Part I - is to investigate the influences of the size of heave plates on the motions of the vessel under various wave conditions. In this part, the size of heave plates is variable, while their underwater distance is fixed. To ease understanding, the RAOs of the vessel in all six directions are shown in Fig.5, which are obtained when the underwater distance is $1 \mathrm{~m}$ and the diameter of the heave plates is respectively $0,0.1,0.2,0.3,0.4$, and $0.5 \mathrm{~m}$. Herein, diameter ' $0 \mathrm{~m}$ ' means that there is no heave plate is applied to the vessel. Considering the motion stability of the vessel can be best assessed when resonant vibration happens, only the calculated RAOs in the resonant regions of the vessel are analysed.

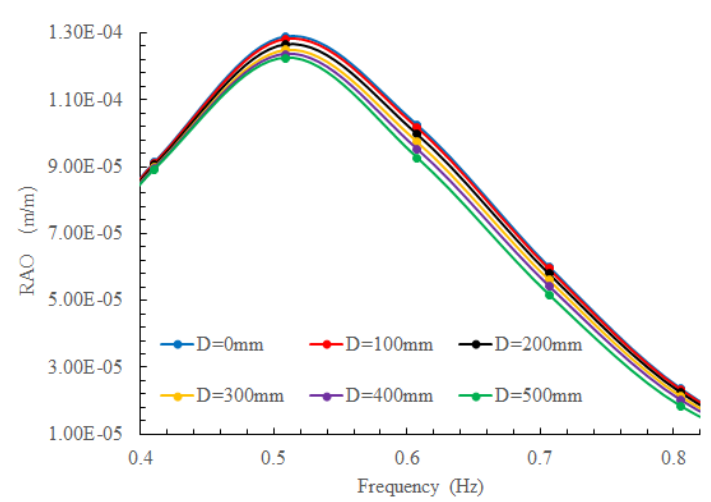

(a) Surge direction

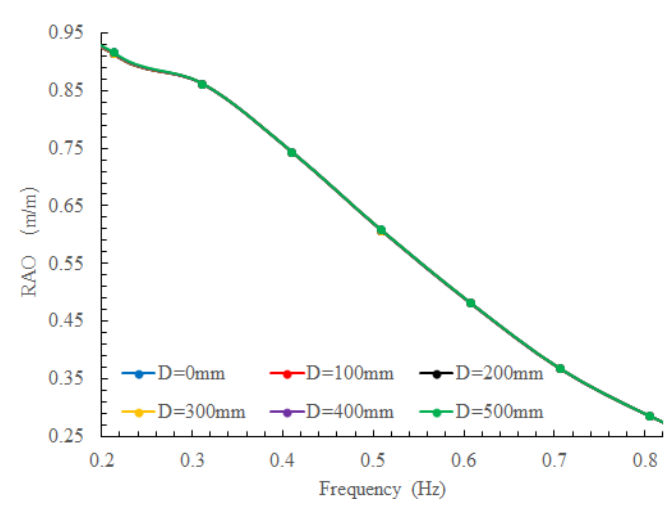

(b) Sway direction 


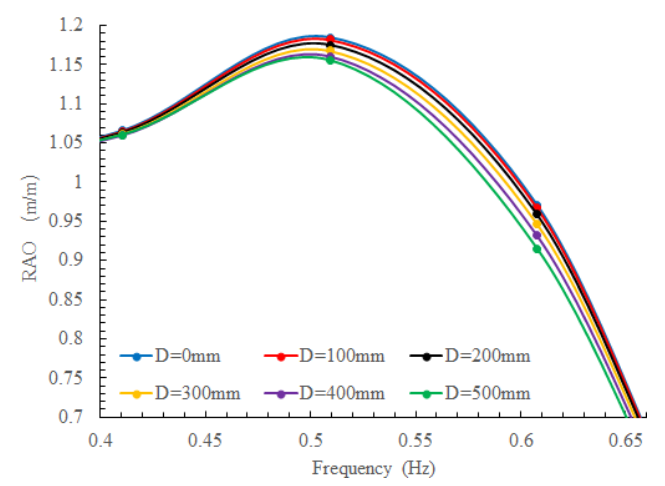

(c) Heave direction

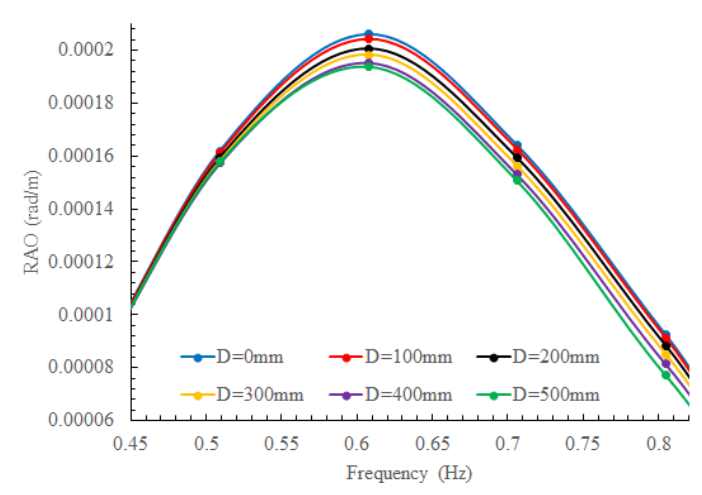

(e) Pitch direction

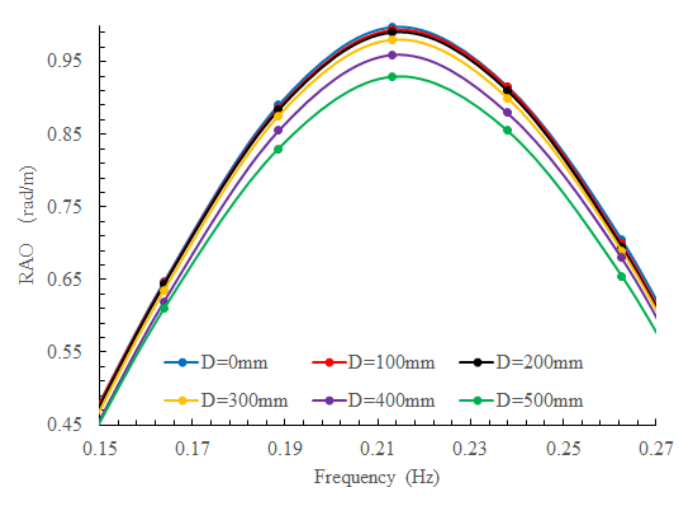

(d) Roll direction

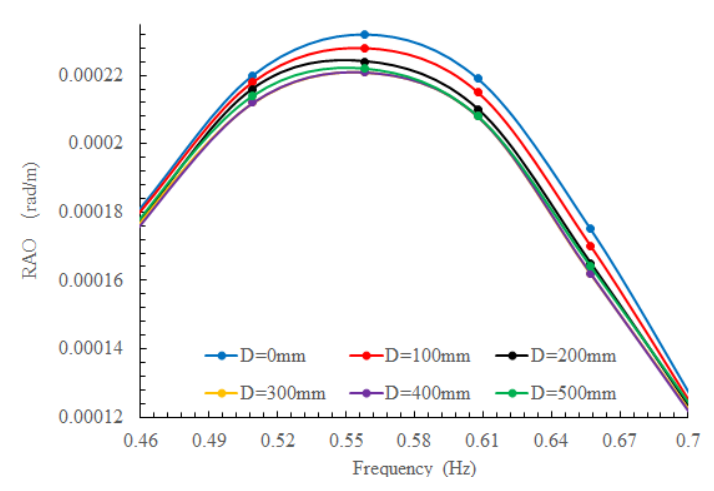

(f) Yaw direction

From Figs. $5 \mathrm{c}$ and d, it is found that heave plates do significantly constrain the motions of the vessel in heave and roll directions. Moreover, the larger the size of the heave plates, the more the motions are reduced. In contrast to the motion reduction in heave and roll directions, Fig.5e indicates that the vessel's pitch motion is less affected by the heave plates although the larger contribution of bigger heave plates to pitch motion reduction at corresponding frequencies can still be observed from the curves. This is because, as mentioned at the beginning of Section 2.2, the sea waves that are considered in the calculations are beam sea waves that approach the vessel from broadside. It is well known that beam sea waves have little influence on the pitch motion of the vessel. Such a phenomenon fully demonstrates that the CFD model developed in this paper is completely right and the its prediction to the vessel's motions is reliable. Such a conclusion is further proved by the RAOs shown in Figs.5a, b and f. Since the beam sea waves approach the vessel from broadside, significant sway motions of the vessel are clearly observed from Fig.5b. However, as shown in Fig.5b, the vessel's sway motion is irrelative to the change of the size of the heave plates. This is because the sway direction damping of the system is nearly not influenced by the heave plates. Likewise, the change in the size of heave plates does not change the system's damping either in surge and yaw directions. Therefore, the influences of the heave plates on the RAOs in these two directions are also very small and ignorable, as shown in Figs.5a and $\mathrm{f}$. 
Part II - is to investigate how the underwater distance of the heave plates affect the motions of the vessel under different wave conditions. Different from the investigations conducted in Part I, the underwater distance of the heave plates is variable, while the size of the plates is fixed. To ease understanding, the RAOs of the vessel, obtained when the diameter of the heave plates is $0.5 \mathrm{~m}$ whilst their underwater distance is respectively 0.5, 0.7, 1.0, 1.2 and $1.5 \mathrm{~m}$, are shown in Fig.6. Considering the motions of the vessel in the directions of heave, roll and pitch are more important to the safe operation of the crew transfer vessel, only the RAOs in these three directions are shown in Fig.6 in order to keep a concise context of the paper.

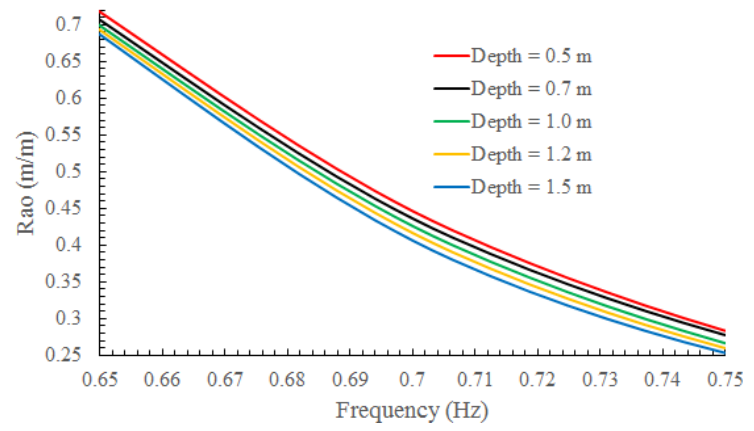

(a) Heave direction

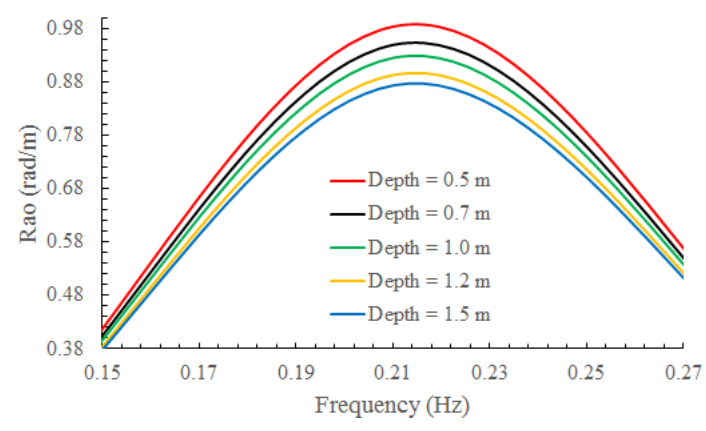

(b) Roll direction

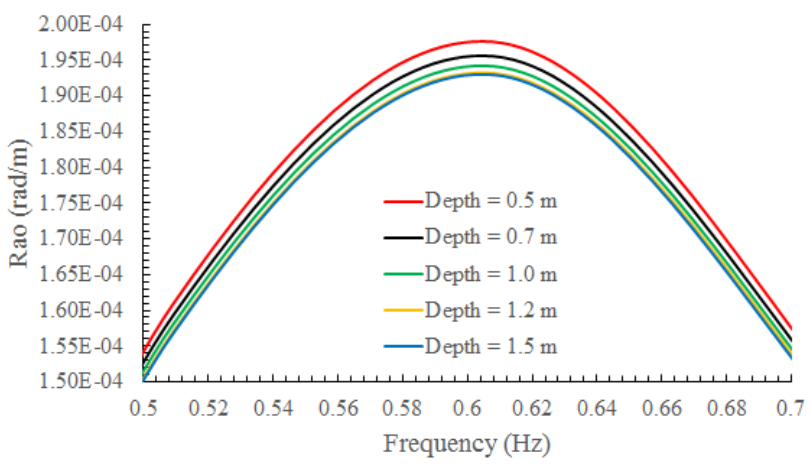

(c) Pitch direction

Fig.6 Influence of the underwater distance of heave plates on the motions of crew transfer vessel

From Fig.6, it is found that the underwater distance of heave plates does have a significant influence on the motion stability of the vessel, i.e. the deeper the heave plates are placed, the more the motions of the vessel are constrained in all these three directions. This is because according to wave theory, the energy of sea wave will decay gradually with the increase of the distance away from free water surface. Consequently, the sea waves will have less influence on the heave plates when they are placed at deeper underwater distance. In the meantime, the hydrodynamic damping of the system will increase with the increase of the underwater distance of the heave plates. Therefore, more motion reduction is observed when the heave plates are placed at deeper water distance. But as observed from Fig.5, the RAO values shown in Fig.6c are much smaller than those in Figs.6a and b, because the 
beam sea waves have significant influences on the heave and roll motions of the vessel, whilst have less influence on the vessel's pitch motion.

\section{Experimental Research}

249

250

\subsection{Testing facilities and data processing method}

In order to verify the findings in the aforementioned numerical research and investigate the actual contribution of the heave plates to stabilizing the motion of the crew transfer vessel, experimental research was further conducted with the aid of the marine testing facilities in the hydro-laboratory of Newcastle University. The towing tank for conducting motion tests, the 'Qualisys' system for data acquisition, and the physical model of the crew transfer vessel equipped with four extension legs and heave plates, are shown in Fig.7. The geometries of the physical model of the vessel and the wave conditions simulated in the experimental tests are listed in Table 3.

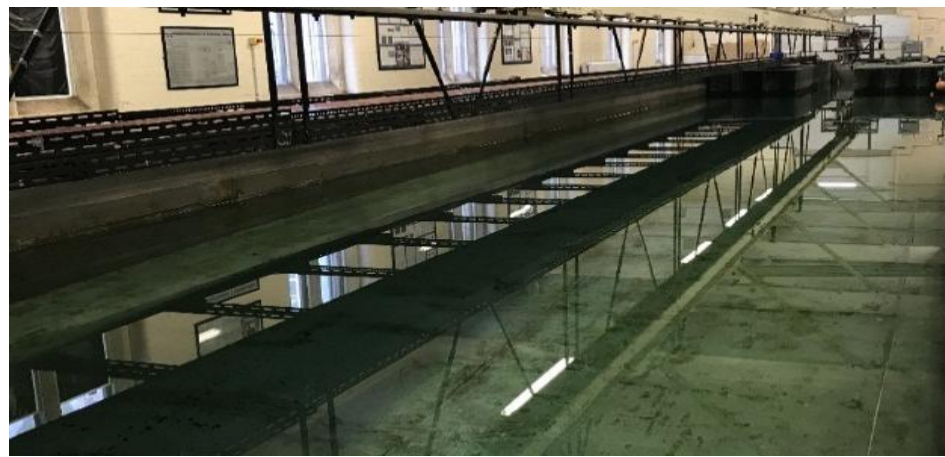

(a) Towing tank for conducting motion tests

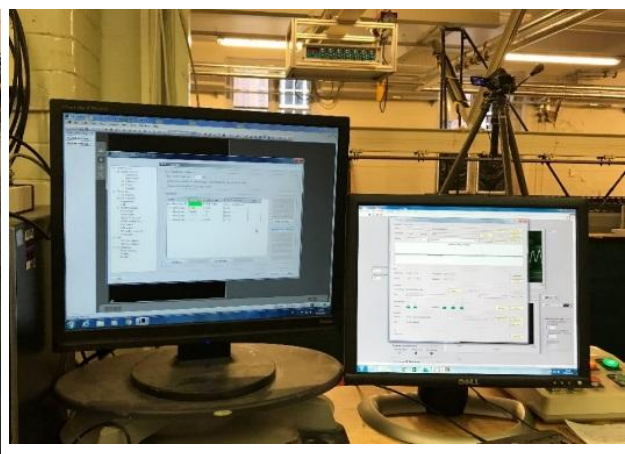

(b) Qualisys system for data acquisition

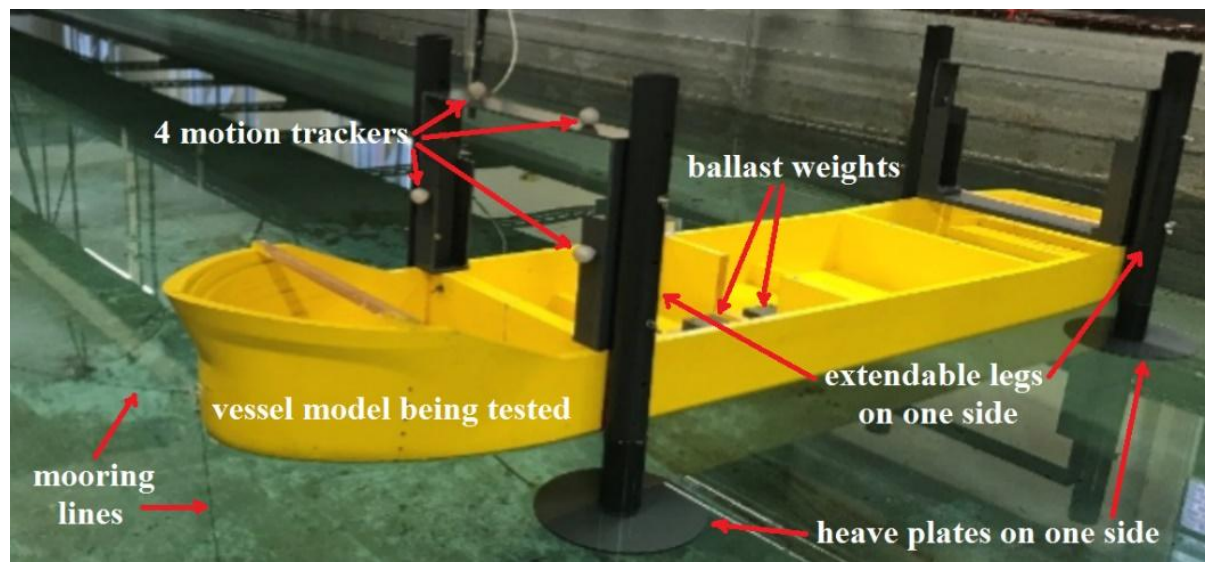

(c) Physical model of the vessel being tested

Fig.7 Testing facilities in the hydro-laboratory of Newcastle University 
Table 3. Geometries of the physical model and sea waves being simulated in the tests

\begin{tabular}{l|c|l|l}
\hline \multicolumn{2}{c|}{ Geometries of the physical model } & \multicolumn{2}{c}{ Wave conditions simulated in the tests } \\
\hline Length & $2 \mathrm{~m}$ & Scenario 1 & Wave period $0.5 \mathrm{~s}$, wave height $0.12 \mathrm{~m}$ \\
\hline Beam & $0.5 \mathrm{~m}$ & Scenario 2 & Wave period $1.0 \mathrm{~s}$, wave height $0.12 \mathrm{~m}$ \\
\hline Draft & $0.1 \mathrm{~m}$ & Scenario 3 & Wave period $1.5 \mathrm{~s}$, wave height $0.12 \mathrm{~m}$ \\
\hline Freeboard & $0.06 \mathrm{~m}$ & Scenario 4 & Wave period $2.0 \mathrm{~s}$, wave height $0.12 \mathrm{~m}$ \\
\hline
\end{tabular}

264

265

266

267

268

269

270

271

272

273

274

275

276

277

278

279

280

Similarly, beam sea wave conditions are considered in the experimental tests. In each scenario of wave condition, the motions of the physical model of the vessel in all six degree of freedom are tested when the underwater distance of the heave plates is $0.05,0.15,0.25$ and $0.35 \mathrm{~m}$ and their diameter is respectively $0,0.05,0.15,0.25$ and $0.35 \mathrm{~m}$. Accordingly, there are total 80 tests are conducted in the experimental research. Considering it is unlikely to show all testing results within the limited context of the paper and the motion stability of the vessel in heave, roll and pitch directions are more important to the safe operation of the crew transfer vessel, only the testing results in these three directions are discussed in the following. To ease understanding, the time waveforms of the vessel motions measured when the wave period $T$ is respectively $1.0 \mathrm{~s}$ and $1.5 \mathrm{~s}$ are illustrated in Fig. 8 as illustrative examples.

From Fig.8, it is seen that regardless of the wave period, the vessel's motions in heave, roll and pitch directions are significantly reduced after the heave plates are applied to the vessel. Moreover, the larger the size of the heave plates, the more the motion are reduced. But as expected, the pitch motions of the vessel are generally much smaller than its roll motions as the waves in the tests are beam sea waves.

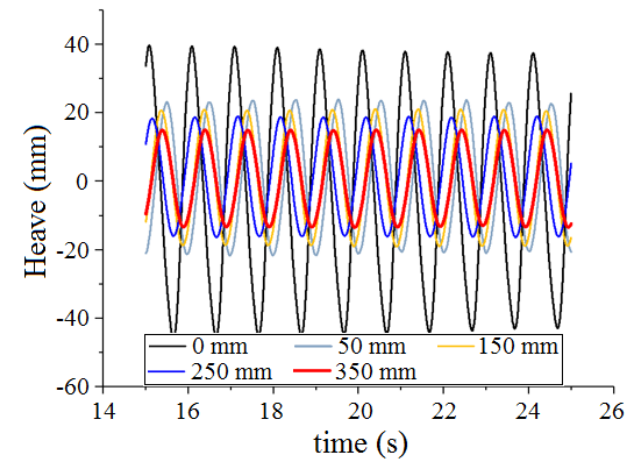

(a) Heave direction, $T=1.0 \mathrm{~s}$

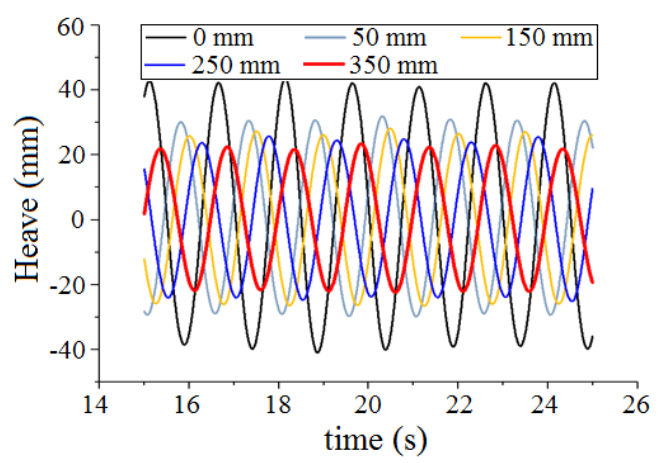

(b) Heave direction, $T=1.5 \mathrm{~s}$ 


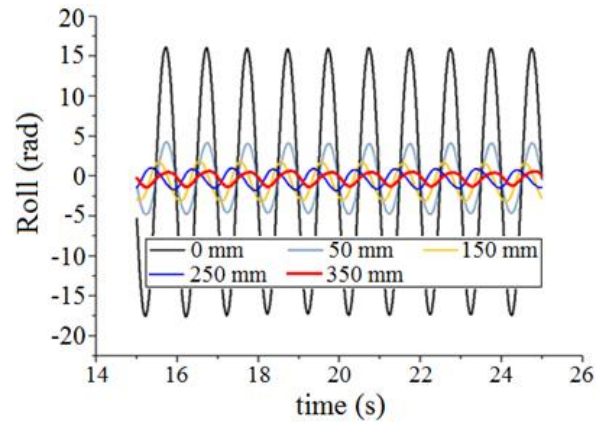

(c) Roll direction, $T=1.0 \mathrm{~s}$

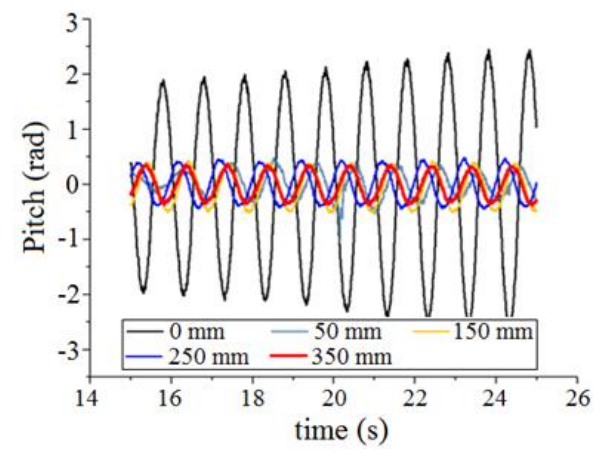

(e) Pitch direction, $T=1.0 \mathrm{~s}$

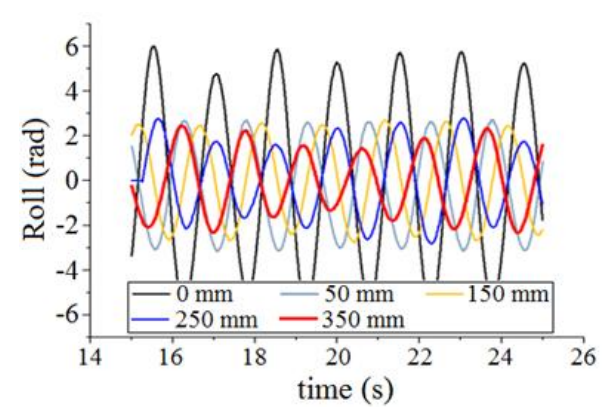

(d) Roll direction, $T=1.5 \mathrm{~s}$

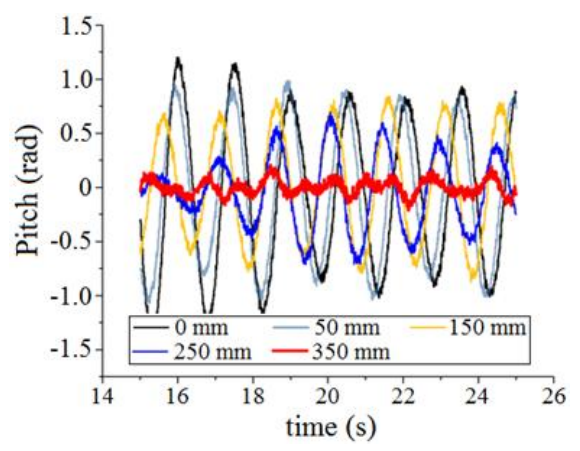

(f) Pitch direction, $T=1.5 \mathrm{~s}$

Fig.8 The measured motions of the physical model of the vessel

To facilitate motion assessment, the RAOs of the vessel in all these three directions are calculated. In theory, when a floating structure is excited by a regular wave with constant amplitude $\zeta_{a}$ and constant frequency $\omega$, its response will be an oscillation of the same frequency $\omega$ and with a constant amplitude $a\left(a \neq \zeta_{a}\right)$. Then, the RAO of the floating structure can be calculated by using equation

$$
\operatorname{RAO}(\omega)=\frac{a(\omega)}{\zeta_{a}(\omega)}
$$

where $\omega=\frac{2 \pi}{T}$ and $\zeta_{a}(\omega)$ are respectively the frequency and amplitude of exciting waves, $a(\omega)$ is the amplitude of the corresponding response of the floating structure.

However, it is noticed from Fig. 8 that in reality the practical response amplitude of the structure is not always constant over time due to various reasons (e.g. the interference of the waves returning from the end of the towing tank). In order to improve the accuracy of RAO calculations, a root-meansquare-value based method is often adopted in the practical calculation. Assume the measured elevation of the exciting wave is $\zeta_{a}(t)(t=0 \sim T)$ and the measured elevation of the structure response is $(t)(t=0 \sim T)$, the RAO can be estimated by [15]

$$
\mathrm{RAO}=\sqrt{\frac{\int_{0}^{T}\left\{[a(t)-\bar{a}]^{2}\right\} d t}{\int_{0}^{T}\left\{\left[\zeta_{a}(t)-\overline{\zeta_{a}}\right]^{2}\right\} d t}}
$$

where $\overline{\zeta_{a}}$ and $\bar{a}$ are the mean values of $\zeta_{a}(t)$ and $a(t)$.

The calculation method described in (4) is simple in calculation and robust against noise. It is however unable to mitigate the negative influences of those sub- and higher orders of frequency 
components in the sea waves on the accuracy of RAO. For this reason, a new RAO assessment method is proposed in the following in order to assure the reliability of the RAO assessment result, i.e.

$$
\operatorname{RAO}(\omega)=\sqrt{\frac{s_{a}(\omega)}{s_{\zeta_{a}}(\omega)}}
$$

where $S_{a}(\omega)$ and $S_{\zeta_{a}}(\omega)$ are the values of the power spectral density of signals $a(t)$ and $\zeta_{a}(t)$ at the fundamental frequency $\omega$ of the exciting waves. They are calculated by

$$
\left\{\begin{array}{l}
S_{a}(\omega)=\int_{-\infty}^{\infty} R_{a, a}(\tau) e^{-i \omega \tau} d \tau \\
S_{\zeta_{a}}(\omega)=\int_{-\infty}^{\infty} R_{\zeta_{a}, \zeta_{a}}(\tau) e^{-i \omega \tau} d \tau
\end{array}\right.
$$

where $i=\sqrt{-1} . R_{a, a}(\tau)$ and $R_{\zeta_{a}, \zeta_{a}}(\tau)$ are the autocorrelation of the measured signals $a(t)$ and $\zeta_{a}(t)$ at the time moment of $\tau$. They can be readily calculated using the following equations

$$
\left\{\begin{array}{l}
R_{a, a}(\tau)=\boldsymbol{E}[a(t) a(t+\tau)]=\lim _{T \rightarrow \infty} \frac{1}{T} \int_{-T / 2}^{T / 2}[a(t) a(t+\tau)] d t \\
R_{\zeta_{a}, \zeta_{a}}(\tau)=\boldsymbol{E}\left[\zeta_{a}(t) \zeta_{a}(t+\tau)\right]=\lim _{T \rightarrow \infty} \frac{1}{T} \int_{-T / 2}^{T / 2}\left[\zeta_{a}(t) \zeta_{a}(t+\tau)\right] d t
\end{array}\right.
$$

where $\boldsymbol{E}[\cdot]$ denotes expected value.

From (5)-(7), it is seen that the value of the calculated RAO is only dependant on the values of the power spectral density of the exciting wave $\zeta_{a}(t)$ and response $a(t)$ at fundamental frequency $\omega$. It is not affected by the other frequency components $n \cdot \omega(n>0)$ contained in sea waves. Therefore, the RAO assessed by using the power-spectral-density based method should be more accurate and reliable than those obtained by using the conventional root-mean-square-value based method.

\subsection{Experimental results}

In order to verify the findings in the numerical research, influences of both the size and the underwater distance of the heave plates on the motions of the crew transfer vessel are investigated in the following. The measured wave and vessel response data are processed by using the method proposed in section 3.1. The resultant RAOs under different wave conditions are shown in Figs.9 and 10. In order to keep a concise context of the paper, only the RAO assessment results obtained when the underwater distance is 0.05 and $0.15 \mathrm{~m}$ are illustrated in Fig.9, and only the RAOs obtained when the diameter of the heave plates is $0.4 \mathrm{~m}$ are shown in Fig. 10 . 


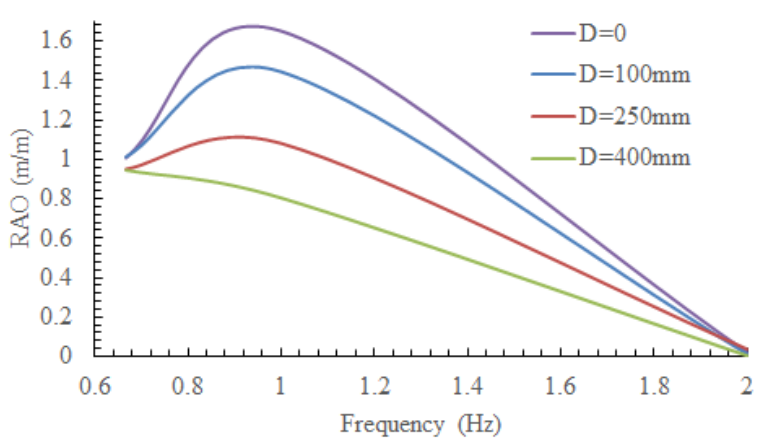

(a) Heave direction, underwater distance is 0.05 $\mathrm{m}$

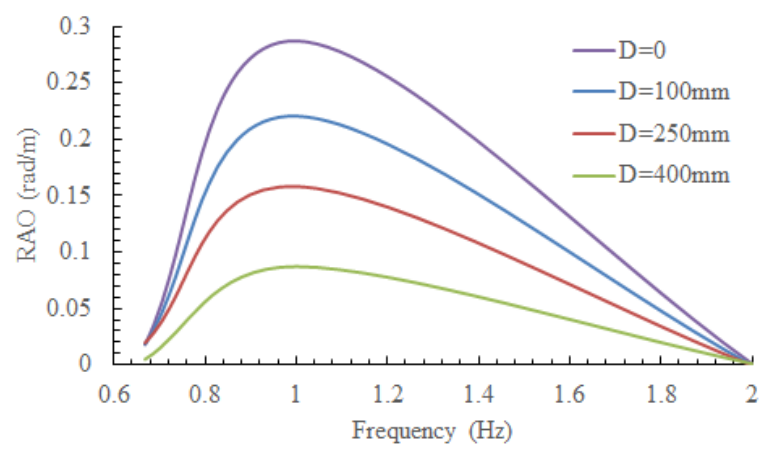

(c) Roll direction, underwater distance is $0.05 \mathrm{~m}$

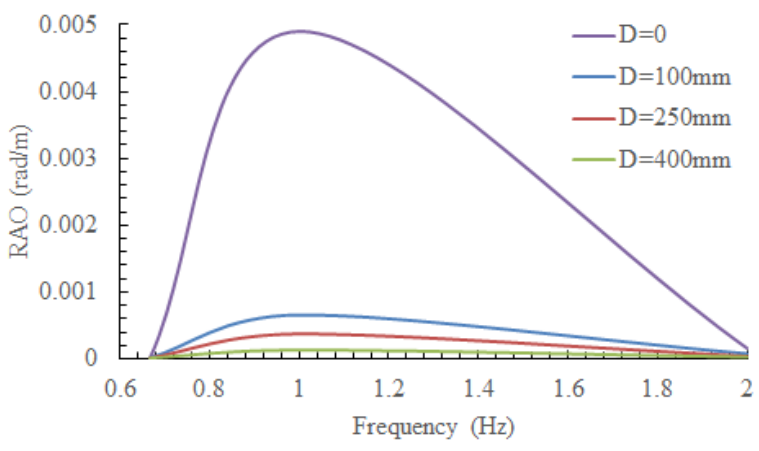

(e) Pitch direction, underwater distance is 0.05 $\mathrm{m}$

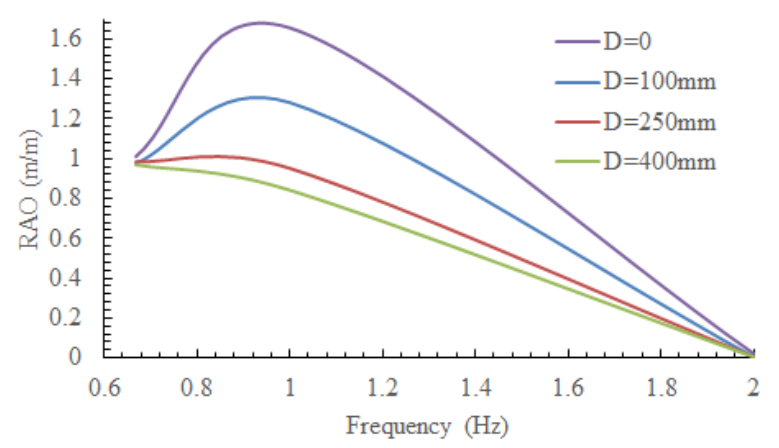

(b) Heave direction, underwater distance is 0.15 $\mathrm{m}$

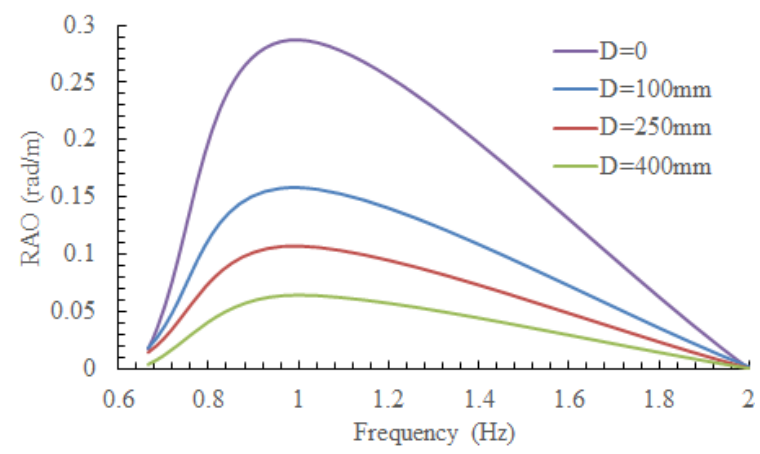

(d) Roll direction, underwater distance is $0.15 \mathrm{~m}$

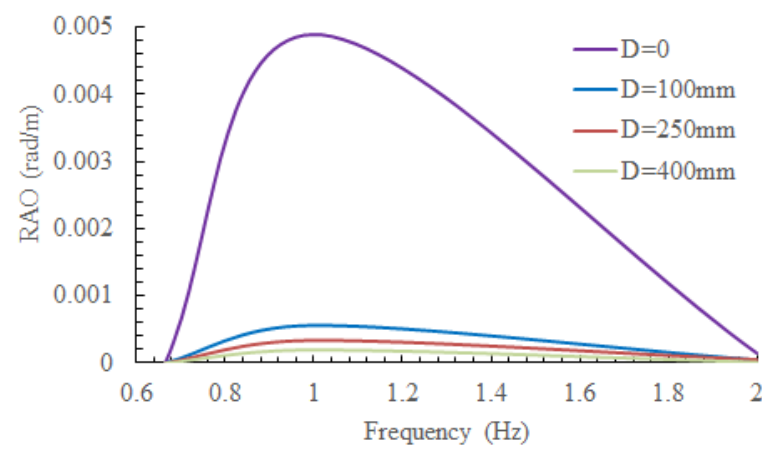

(f) Pitch direction, underwater distance is $0.15 \mathrm{~m}$

Fig.9 Influences of the size of heave plates at underwater distances $0.05 \mathrm{~m}$ and $0.15 \mathrm{~m}$

From Fig.9, it is seen that regardless of the underwater distance that the heave plates are placed, the motions of the vessel in heave, roll and pitch are significantly reduced after the heave plates are applied to the vessel. Moreover, the larger the size of the heave plates, the more the motions of the vessel are constrained, particularly in the resonant frequency region of $0.6-2 \mathrm{~Hz}$. Such a phenomenon is completely in consistence with the findings in the numerical research. In addition, through comparing the RAO curves corresponding to different sizes of heave plates, it is noticed that the application of the heave plates more or less decreases the values of the natural frequencies of the vessel. Moreover, the larger the size of the heave plates, the more the natural frequency of the vessel decreases. This is because the heave plates not only increase the physical mass of the vessel but also 
increase the added mass of the vessel. As a consequence, the natural frequency of the whole 'vessel + heave plates' system is correspondingly decreased. Additionally, the comparison of Fig.5 and Fig.9 interestingly indicates that the effect of heave plate on the vessel's motion stability can be more clearly observed from the experimental results in Fig.9 rather than from the numerical simulation results in Fig.5. This is because water is a viscous fluid. The viscosity of water will amplify the motion reduction effect of the heave plates. However, the viscosity of water is neglected in the CFD calculations to ensure the differential hydrodynamics equations to be tractable.

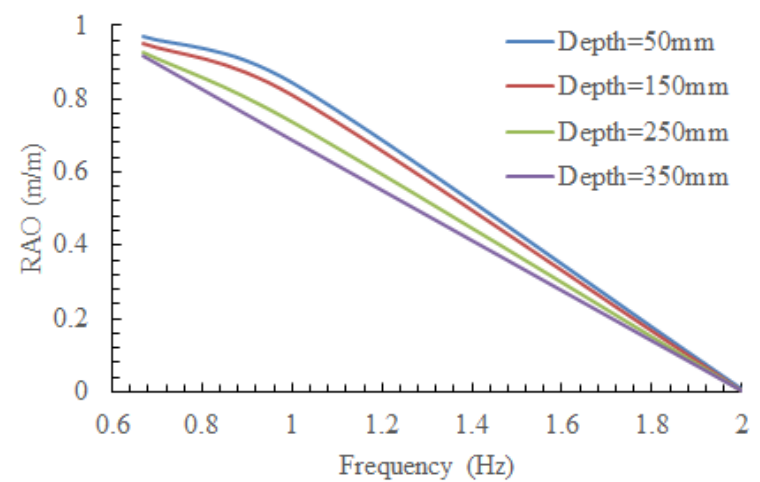

(a) Heave direction

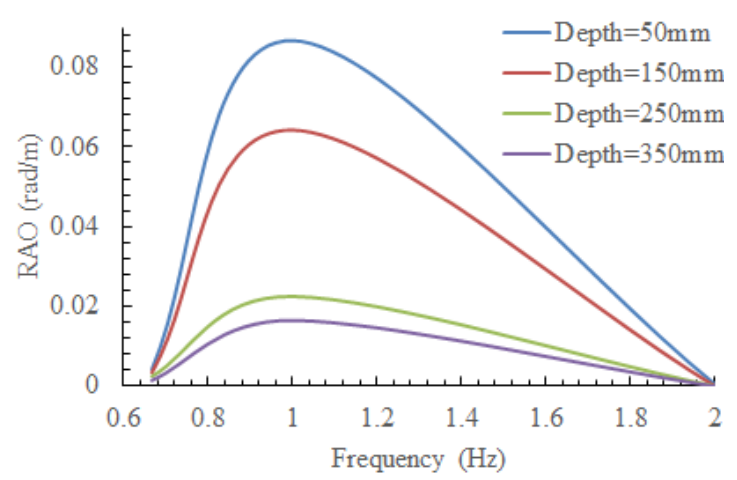

(b) Roll direction

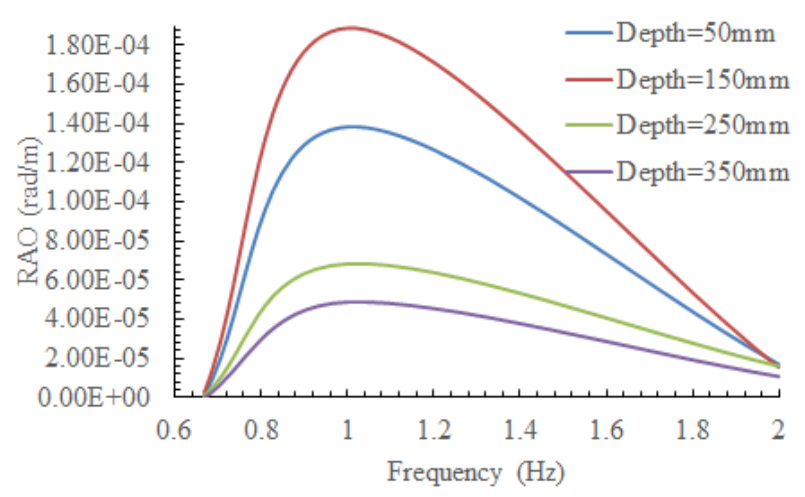

(c) Pitch direction

Fig.10 Influences of the underwater distance of heave plates

From Fig.10, it is found that the distance that the heave plates are placed under water surface does have a significant influence as well on the motions of the vessel. Moreover, the deeper that the heave plates are placed under water surface, the more the motion of the vessel can be constrained by the heave plates. Such a phenomenon agrees very well with those observed from the numerical simulation results shown in Fig.6. Additionally, as predicted in Fig.6, it is found from Fig.10 that the beam sea waves do have more significant influence on the vessel's heave and roll motions than on its pitch motion. 
Crew transfer vessels are playing a vital role in the operation and maintenance of offshore wind farms. However, the present crew transfer vessels have limited capability to provide safe transfer between the vessel and wind turbines. This significantly lowers the efficiency of offshore wind farm maintenance activities. In view of this, a cost-effective motion stabilization technique is studied in this paper by using both numerical simulation and experimental testing approaches. From the researches described above, three key conclusions can be drawn:

(1) Heave plate does show an outstanding capability in stabilizing the motions of offshore wind farm crew transfer vessel. Moreover, the larger the size of heave plates, the more the motions of the vessel will be constrained particularly in the resonant frequency region of the vessel;

(2) The installation of the heave plates also has influence on their motion stabilization effect. The deeper the heave plates are placed under water surface, the more the motions of the vessel will be reduced;

(3) The comparison of the numerical simulation and experimental testing results has disclosed that the viscosity of water can further amplify the motion stabilization effect of heave plates;

\section{Acknowledgement}

373 The work reported in this paper was supported by National Natural Science Foundation of 374 China with the reference numbers of 11772126 and 11632011, and State Key Laboratory of 375 Mechanical System and Vibration at Shanghai Jiaotong University with the reference number of MSV201702.

\section{References}

379 1. Global Wind Energy Council, Global wind statistics 2017, 14 ${ }^{\text {th }}$ February 2018.

380 2. UK Trade \& Investment, UK Offshore wind: Opportunities for trade and investment, 2015.

381 3. Dalgic, Y.; Lazakis, I.; Turan, O., Vessel charter rate estimation for offshore wind O\&M 382 activities, International Maritime Association of Mediterranean (IMAM 2013), October 14-17, 2013, A Coruna, Spain.

4. 4Coffshore, Wind farm service vessels (WFSVs) -An analysis of supply and demand, January 2015.

5. Vroon Offshore Services and Ampelmann join forces for Arkona wind farm project, January 15, 2018. https://www.ampelmann.nl/news/vroon-offshore-services-and-ampelmann-join-forces-forarkona-wind-farm-project. Accessed on 28 February 2018. 
6. Tavner, P.J.; Xiang, J.P.; Spinato, F., Reliability analysis for wind turbines. Wind Energy 2006, 10(1), 1-18.

7. Ribrant, J.; Bertling, L., Survey of failures in wind power systems with focus on Swedish wind power plants during 1997-2005. IEEE Transactions on Energy Conversion 2007, 22(1), 167-173.

8. Feng, Y.; Tavner, P.J.; Long, H., Early experience with UK round 1 offshore wind farms. Proceedings of Institution of Civil Engineers - Energy 2010, 163(NE4), 167-181.

9. Tavner, P.J., Offshore wind turbines - Reliability, availability and maintenance. The Institution of Engineering and Technology, 2012.

10. Tzeng, C.Y.; Wu, C.Y., On the design and analysis of ship stabilizing fin controller. Journal of Marine Science and Technology 2000, 8(2), 117-124.

11. Perez, T., Ship motion control. Springer-Verlag, London, 2005.

12. Cavalletti, M.; Ippoliti, G.; Longhi, S., Adaptive nonlinear control for vessel roll stabilization. IFAC Proceedings Volumes 2007, 40(17), 44-49.

13. Tao, L.; Cai, S., Heave motion suppression of a spar with a heave plate. Ocean Engineering 2004, 31, 669-692.

14. Subbulakshmi, A.; Sundaravadivelu, R., Heave damping of spar platform for offshore wind turbine with heave plate. Ocean Engineering 2016, 12, 24-36.

15. Wang, J., Research on the innovative techniques to stabilising crew boat in offshore wind farm. MSc Dissertation, Newcastle University, 2017. 